\title{
Extracellular Vesicles: Emerging Therapeutics in Cutaneous Lesions
}

\author{
Yu Li (iD ${ }^{1-3}$ \\ Qing Xiao ${ }^{1-3}$ \\ Jie Tang ${ }^{2-4}$ \\ Lidan Xiong ${ }^{2-4}$ \\ $\mathrm{Li} \mathrm{Li}^{\mathrm{l}-4}$ \\ 'Department of Dermatology, West \\ China Hospital, Sichuan University, \\ Chengdu, 61004I, People's Republic of \\ China; ${ }^{2}$ Cosmetics Safety and Efficacy \\ Evaluation Center, West China Hospital, \\ Sichuan University, Chengdu, 61004I, \\ People's Republic of China; ${ }^{3}$ NMPA Key \\ Laboratory for Human Evaluation and Big \\ Data of Cosmetics, Chengdu, 61004I, \\ People's Republic of China; ${ }^{4}$ Sichuan \\ Engineering Technology Research Center \\ of Cosmetic, Chengdu, 61004I, People's \\ Republic of China
}

Correspondence: $\mathrm{Li} \mathrm{Li}$

Department of Dermatology, West China Hospital, Sichuan University, Chengdu, Sichuan, 61004I, People's Republic of China

Email lilihx_scu@scu.edu.cn

Lidan Xiong

Cosmetics Safety and Efficacy Evaluation

Center, West China Hospital, Sichuan

University, No. 5, Gong Xing Road,

Chengdu, Sichuan, 61004I, People's

Republic of China

Email beardan0505@163.com

\begin{abstract}
Extracellular vesicles (EVs), as nanoscale membranous vesicles containing DNAs, RNAs, lipids and proteins, have emerged as promising diagnostic and therapeutic agents for skin diseases. Here, we summarize the basic physiology of the skin and the biological characteristic of EVs. Further, we describe the applications of EVs in the treatment of dermatological conditions such as skin infection, inflammatory skin diseases, skin repair and rejuvenation and skin cancer. In particular, plant-derived EVs and clinical trials are discussed. In addition, challenges and perspectives related to the preclinical and clinical applications of EVs are highlighted.
\end{abstract}

Keywords: extracellular vesicles, skin diseases, plant, clinical trials

\section{Introduction}

Extracellular vesicles (EVs) are a heterogeneous group of nano-sized membranous vesicles released by cells and can be broadly divided into exosomes (50$150 \mathrm{~nm}$ ) and microvesicles $(50-1000 \mathrm{~nm})$, based on their biogenesis and biophysical properties (Figure 1A). ${ }^{1}$ In addition, ectosomes, membrane particles and apoptotic bodies were also distinguished. ${ }^{1,2}$ Although initially thought to be cellular debris, EVs are now increasingly being recognized for their roles in intercellular communication and circulating biomarkers of disease since their cargo mainly includes DNAs, RNAs, proteins and lipids. ${ }^{1}$ In addition, EVs can be modified by manipulating their parent cells, through either genetic or metabolic engineering or by importing exogenous material into EVs. ${ }^{3}$ Therefore, EVs can be used as nanovectors, after re-engineering. The present article summarizes the biosynthesis of EVs and highlights latest research on the use of EVs in dermatological applications, including infectious diseases, immune skin disorders, pigmentation, alopecia, wound healing, scars, skin rejuvenation and skin cancer (Figure 2). Notably, the review particularly focuses on the use of plantderived EVs in dermatology.

The skin is the largest body organ by mass and the first line of defense as it acts as a barrier that protects the body against harmful external environmental factors such as pathogens, mechanical damage and Ultraviolet (UV) radiation (Figure 1B). ${ }^{4}$ Since the skin has a variety of complex components and physiological functions, interference with its normal structure and function can cause various skin abnormalities including inflammation, immune skin disorders and skin aging. Several methods have been used to improve the skin's condition and treat skin diseases, including use of cosmetics, medicine, laser therapy and cell therapy. ${ }^{5}$ Nonetheless, 


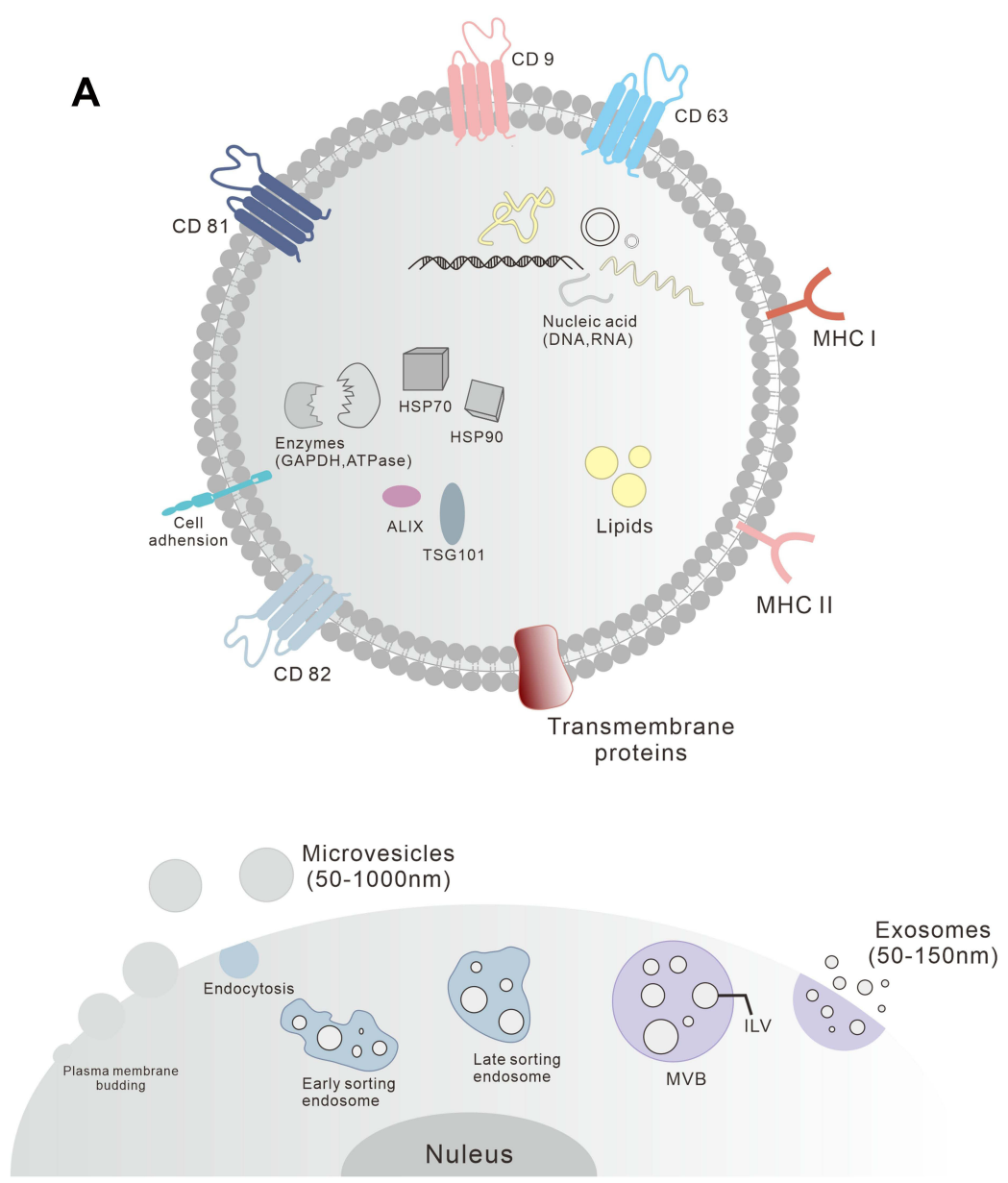

\section{B}

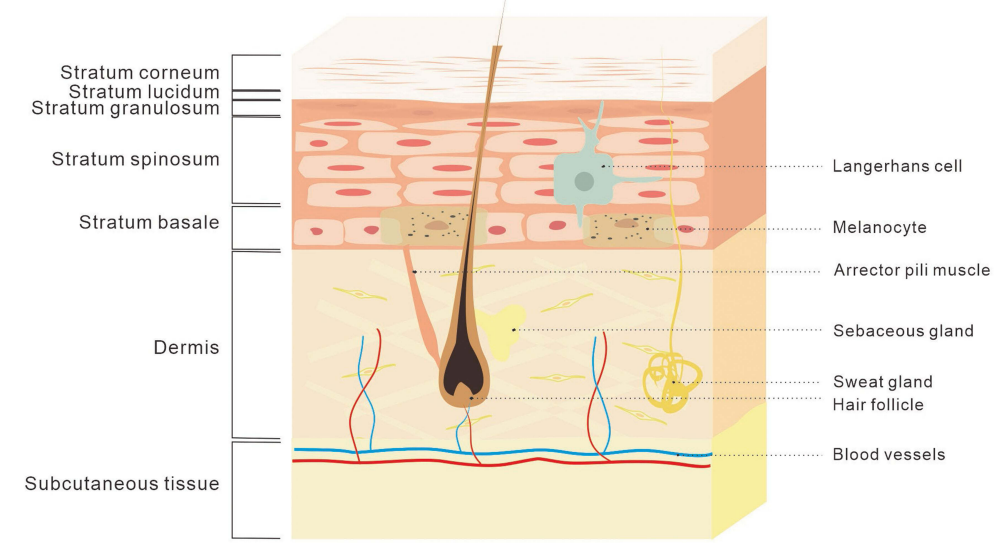

Figure I The skin structure and the molecular composition of EVs. (A) The two major categories of EVs: exosomes and microvesicles. Microvesicles are released through plasma membrane budding. Exosomes originate from the endosomal pathway by the formation of the ESEs, LSEs, and ultimately MVBs, which contain ILVs. As bilayer nanovesicles, EVs pack a variety of cellular components, including nucleic acids (DNAs, RNAs), biogenesis-related proteins (ALIX, TSGI0I), heat shock proteins (HSP70, HSP90), enzymes (GAPDH, ATPase), lipids, adhesion molecules, receptors, and various tissue-specific proteins involved in antigen presentation as transmembrane proteins (CD9, CD63, CD8I, CD82) and MHC-I and MHC-II. (B) The three layers of the skin: epidermis, dermis and subcutaneous tissue.

Abbreviations: EVs, extracellular vesicles; ESEs, early sorting endosomes; LSEs, late sorting endosomes; MVBs, multivesicular bodies; ILBs, intraluminal vesicles; MHC, major histocompatibility complex.

these methods have not achieved the ideal effect and may have side-effects. Therefore, it is critical to develop efficient and safe therapeutics for skin repair and regeneration. This review gives an overview of existing evidence and benefits of EVs-based nanomedicine for clinical use. 


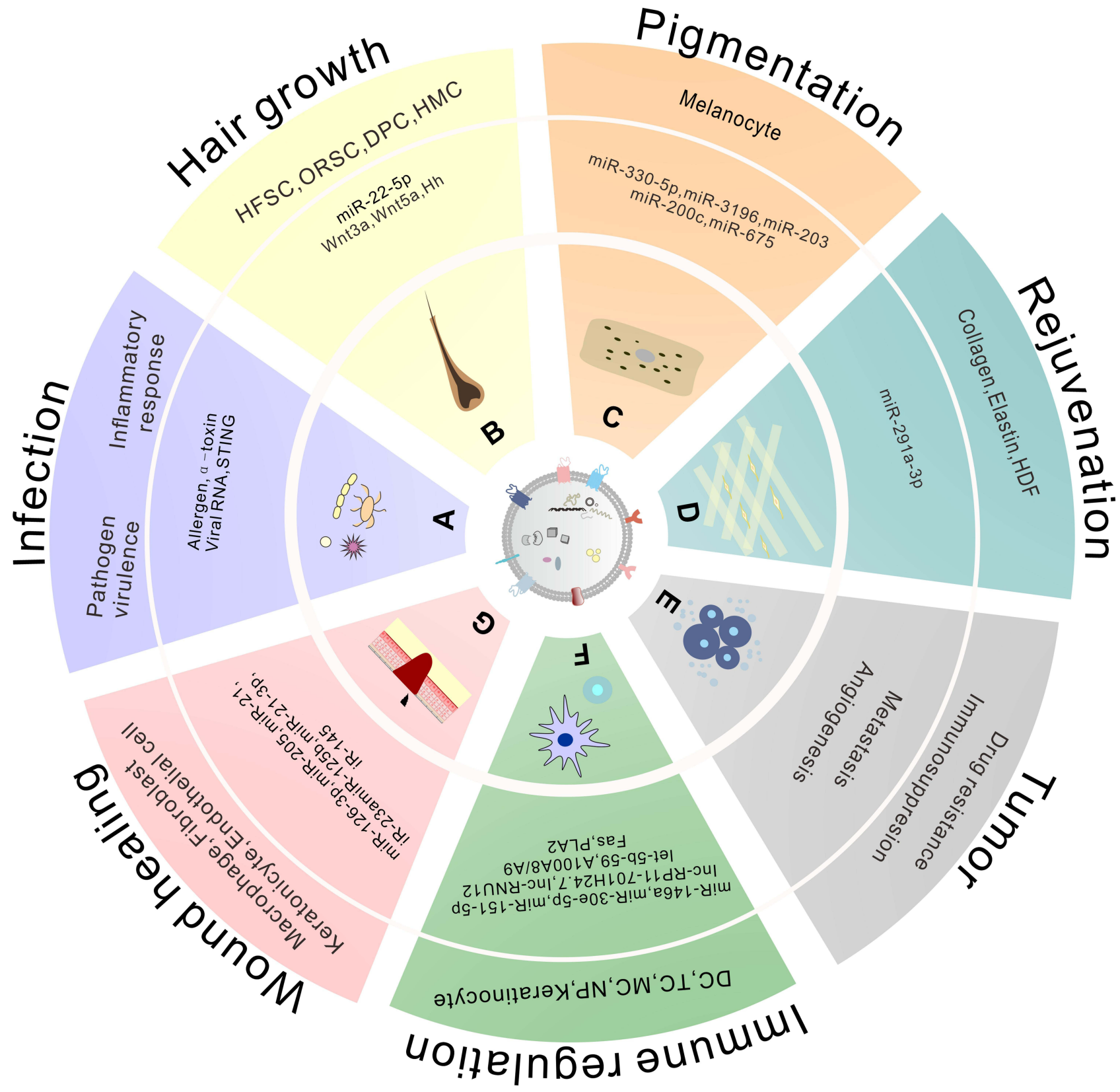

Figure 2 The contents and roles of EVs in cutaneous lesions.

Abbreviations: STING, stimulator of IFN genes; HFSC, hair follicle stem cell; ORSC, outer root sheath cell; DPC, dermal papilla cell; HMC, hair matrix cell; HDF, human dermal fibroblast; DC, dendritic cell; TC, T cell; MC, mast cell; NP, neutrophil; PLA2, phospholipase A2.

\section{Skin and Skin Derived Extracellular Vesicles}

The skin is made up of three layers: the epidermis, dermis and hypodermis. ${ }^{6}$ The epidermis is the outermost layer and is primarily composed of keratinocytes. In addition, keratinocytes proliferate and differentiate to renew the epidermis and ultimately form the stratum corneum, which acts as the main skin barrier. ${ }^{7}$ Other cells in the basal layer of the epidermis include melanocytes, Merkel cells and Langerhans cells. ${ }^{4,6}$
The dermis is separated from epidermis by a basement membrane. It is mainly composed of the extracellular matrix (ECM, mainly collagen fibers) and fibroblasts, providing strength and elasticity to the skin. ${ }^{8}$ Dermal fibroblasts differentiate from mesenchymal cells and are responsible for the synthesis and degradation of ECM proteins. The dermis also contains a wide range of immune cells (such as macrophages, dermal dendrocytes and mast cells), skin appendages, small blood vessels and sensory nerves. ${ }^{9}$ 
The hypodermis is the innermost layer of the skin and is also called the subcutaneous tissue. It is composed of adipocytes, mesenchymal stem cells (MSCs), connective tissue and blood vessels. ${ }^{5,7}$ This layer provides protective pads and serves as an energy storage pool for the body. Additionally, adipocytes produce bioactive lipid mediators and peptide hormones for other skin cells to participate in hair growth, inflammation and wound healing. ${ }^{7,10}$

Most of the skin cells mentioned above have been reported to release EVs involved in intercellular communication in the skin. ${ }^{5,11}$ For instance, keratinocytes which make up $90 \%$ of the cells in the epidermis, can communicate with other skin cells such as fibroblasts, melanocytes and immune cells through EVs. ${ }^{12,13}$ It was also reported that keratinocyte-EVs can stimulate the expression of metalloproteinase-1 (MMP1) in dermal fibroblasts to modify the ECM. ${ }^{12}$ In addition, keratinocyte-EVs and human immortalized keratinocyte (HaCaT)-EVs stimulate fibroblasts migration and induce fibroblast-mediated endothelial tube formation by activating the ERK1/2, JNK, Smad, and p38 signaling pathways, hence mediating wound healing. ${ }^{14}$ Moreover, keratinocyte-EVs can affect other keratinocytes, macrophages, dendritic cells and neutrophils during skin inflammation. ${ }^{15}$ Additionally, keratinocyte-EVs carrying selected microRNAs (miRNAs) modulate melanogenesis in melanocytes. ${ }^{16-18}$ However, EVs derived from other skin cells can also influence keratinocytes. A previous study reported that during cellular aging, senescent dermal fibroblasts released EVs into keratinocytes, inhibiting the differentiation of keratinocytes and barrier function, ${ }^{19}$ thus impairing skin homeostasis. It was also shown that melanocyte-EVs stimulated the proliferation of keratinocytes after UV exposure and might affect epidermal renewal. ${ }^{20}$ Furthermore, dermal fibroblasts and Dermal Papilla Cells (DPCs) have the capacity to enhance hair growth through EVs and this will be discussed in detail in the subsequent sections. ${ }^{21,22}$ In addition to cutaneous lesions, skin cell-derived EVs can also be used to treat other diseases. For example, skin-derived precursor Schwann cells (SKP-SCs) have been reported to have a neuroprotective effect in the peripheral nervous system. Previous research showed that SKP-SC-EVs could not only promote axonal regrowth and motoneuronal regeneration via the $\mathrm{Akt} / \mathrm{mTOR} / \mathrm{p} 70 \mathrm{~S} 6 \mathrm{~K}$ pathway but also improve the growth and survival of sensory neurons via the PTEN/PI3K/Akt axis. ${ }^{23,24}$

EVs can also be isolated from all body fluids, including blood, ${ }^{25}$ breast milk, ${ }^{26}$ urine, ${ }^{27}$ saliva ${ }^{28}$ and cerebral spinal fluid. ${ }^{29}$ And viruses, bacteria, parasites and fungi release EVs in the process of infection. ${ }^{30}$ Interestingly, although plant-EVs were identified as early as $1967,{ }^{31}$ their roles in cell-to-cell communication and therapeutic potential have only been reported recently. ${ }^{32}$

\section{Plant-EVs in Cutaneous Diseases}

Although plant-EVs were identified as early as $1967,{ }^{31}$ little was known about them until recently. Existing evidence suggests that plant-EVs play a role in plant defense and plant-microbe symbiosis, ${ }^{32}$ Additionally, they not only contribute to plant crosstalk but also to inter-kingdom communication. ${ }^{33}$ In fact, plant-EVs have similar characteristics (including biogenesis) to mammalian and bacterial EVs. However, no reports exist on immunogenic responses induced by plant-EVs, suggesting that they may be safe and biocompatible, but the immunogenicity and biocompatibility of each EV formulation must be evaluated in vitro and in vivo. ${ }^{34}$ For example, EVs from four plants-Dendropanax morbifera (DM), Pinus densiflora (PD), Thuja occidentalis (TO), and Chamaecyparis obtusa (CO) were evaluated the cytotoxic effects of various tumor cell types. ${ }^{35}$ DM-EVs and PD-EVs were cytotoxic toward malignant skin tumor cells but not toward normal cells. In contrast, TO-EVs and CO-EVs showed no cytotoxic effects on most tumor cells. ${ }^{35}$

Additionally, studies have demonstrated that EVs derived from various plants, including ginger, grapefruit, grapes, carrot, orange, strawberry, wheat, Arabidopsis leaves, broccoli and citrus lemon have a wide range of therapeutic roles including immunological modulation, tumor suppression and hepatoprotection..$^{32,33,36}$ For example, Teng et al reported that Ginger Exosome-like Nanoparticles (GELNs) were preferentially taken up by Lactobacillaceae in a GELN lipid-dependent manner and contained microRNAs that targeted various genes in Lactobacillus rhamnosus (LGG). ${ }^{37}$ It was also shown that GELN-RNAs can ameliorate mouse colitis through IL-22-dependent mechanisms and this was linked to improvement of barrier function. ${ }^{37}$ You et al reported that nanovesicle isolated from cabbage (Cabex) and red cabbage (Rabex) promoted mammalian cell proliferation and suppressed inflammation in immune cells and apoptosis in human keratinocytes and fibroblasts. ${ }^{38}$ Moreover, a recent study reported that broccoli-derived EVs have the capacity to encapsulate fluorescent products into keratinocytes and penetrate into deep skin layers, ${ }^{39}$ 
highlighting plant-EVs may potentially be used for transdermal drug delivery.

However, there are few reports on the role of plant-EVs in cutaneous diseases. For instance, Şahin et al investigated the effect of wheat-derived exosomes on the process of wound healing. ${ }^{40}$ The exosomes derived from wheat grass juice affected the proliferation and migration of endothelial, epithelial and dermal fibroblast cells, in a dose-dependent manner, in vitro. And real time-PCR analysis showed that there was an increase in the mRNA expression of type I collagen. Wheat exosomes also enhance the formation of tube-like structures, indicating that they play an important role in vascularization during wound healing.

Ginseng is a traditional herbal medicine that is mostly used in eastern Asian countries. A previous study investigated the biological effects of EVs from Ginseng roots (GrEVs) or the culture supernatants of Ginseng cells (GcEVs) derived from Panax ginseng C.A. Meyer, on human skin cells. ${ }^{41}$ The results showed that GrEVs or GcEVs had anti-senescence and anti-pigmentation effects on human dermal fibroblasts or human melanocytes treated with UVB radiation, respectively, by downregulating senescence-associated- $\beta$-galactosidase (SA- $\beta$-Gal) activity, SA markers and melanogenesis-related proteins.

Another study investigated the anti-melanogenic effects of EVs extracted from the leaves and stems of Dendropanax morbifera. ${ }^{42}$ The Leaf-derived EVs (LEVs) and Stem-derived EVs (SEVs) reduced the levels of melanin and Tyrosinase (TYR) activity in the B16-BL6 mouse melanoma cell line, in a dose-dependent manner. Both the LEVs and SEVs exerted a greater whitening effect on melanoma cells than arbutin, without any cytotoxicity, by regulating the genes and proteins related to melanogenesis. Such included the Melanogenesis-associated Transcription Factor (MITF), TYR, Tyrosinase-related Protein (TRP)-1 and TRP-2. Similarly, LEVs exerted a stronger inhibitory effect on melanin synthesis than arbutin, in a human epidermis model.

Similar to EVs from other kingdoms, plant-EVs can also be re-engineered to form drug delivery nanoplatforms, referred to as "Plant-EVs-derived nanovectors". 43 Вy modifying or loading cargo on the surface of EVs, plantEVs can achieve a powerful biological potential. ${ }^{33,36}$ Additionally, some conservative ligands on the surface of EVs can function as bio-imaging tags. ${ }^{33}$ For instance, it was reported that grapefruit-derived nanovectors labeled with the DiR dye, could be tracked in vivo through fluorescence. ${ }^{43}$

\section{EVs in Dermatology Infectious Diseases}

During viral, bacterial, parasitic and fungal infections, EVs can be released from both the pathogen and the host. ${ }^{30,44}$ EVs derived from host cells can activate immune responses in order to control infection. On the other hand, EVs derived from pathogens can convey pathogen molecules in order to regulate host defense and immunity or induce immunosuppression during infection. ${ }^{30}$ Due to their numerous biomolecules, EVs may potentially be used in treating infections, drug delivery, vaccine preparations and as diagnostic markers. ${ }^{30,41}$

The Herpes Simplex Virus type-1 (HSV-1) is a common pathogen that affects more than $80 \%$ of the world's population. The virus primarily infects mucoepithelial cells and resides in the neuron ganglia. ${ }^{45}$ A previous study by Bello-Morales et al showed that the EVs released by HSV-1-infected cells were endocytosed by naive cells, suggesting that the virus might use EVs to evade the host's immune responses. In addition, EVs carry viral RNA and Stimulator of IFN Genes (STING) to uninfected cells, indicating that HSV-1 might restrict the spread of infection from cell-to-cell in order to control its virulence and enhance its ability to spread between individuals. $^{46}$

Additionally, skin infection with Staphylococcus aureus is known to enhance atopic dermatitis (AD), although the exact mechanism is still unknown. ${ }^{47}$ Recent research showed that EVs from $S$. aureus upregulate the levels of pro-inflammatory cytokines in vitro and in vivo, with a mixed Th1/Th2 and Th17 type immune response in ADlike skin lesions. ${ }^{47,48}$ Furthermore, $S$. aureus releases EVs that carry the pore-forming $\alpha$-toxin. ${ }^{44} \mathrm{HaCaT}$ targeted by these EVs can endocytose their toxin-containing cell membranes and conversely form exosomes, which have both mono-and multi-meric toxins and could be activated after being taken up by naive HaCaT. ${ }^{44,49}$ This showed that EVs are closely associated with the pathogenicity of $S$. aureus and $\mathrm{AD}$.

Acne vulgaris is the most common skin condition in young people and Propionibacterium acnes contributes to the development of acne. ${ }^{50}$ Choi et al showed that P.acnesderived EVs (PEVs) can induce acne-like phenotypes in both keratinocytes and a human skin model by triggering the release of inflammatory cytokines and dysregulating epidermal differentiation through the TLR2-dependent signaling pathway. ${ }^{50}$ 
Fungi from the Malassezia species are among the most dominant members of the human skin microbiota. It was reported that Malassezia sympodialis can release EVs, which carry allergens from the fungus and induce inflammatory cytokine responses with significantly high production of IL-4 in peripheral blood mononuclear cells from patients with $\mathrm{AD} .{ }^{51}$ In addition, these EVs can upregulate the expression of the intercellular adhesion molecule-1 (ICAM-1) on human keratinocytes, possibly attracting immune cells. These findings suggested that EVs may be important in cutaneous defenses against $M$. sympodialis. ${ }^{51}$ Moreover, other fungi such as Cryptococcus neoformans and Candida albicans can also release EVs to promote infection. ${ }^{52}$ However, more studies are required to elaborate the mechanism underling the role of EVs in fungal infections.

Leishmaniasis is a poverty-related and vector-borne parasitic disease that is associated with approximately 0.7-1 million new cases every year, from nearly 100 endemic countries. ${ }^{53}$ Previous research demonstrated that Leishmania secrets microvesicles into the extracellular space which in turn deliver cargo to host target cells, mediating immunosuppression and invasion of the parasite. $^{54}$ Moreover, it was reported that Leishmania EVs released within the guts of sandflies exacerbated cutaneous leishmaniasis by upregulating the levels of IL-23/IL-17 in the lymph nodes of Balb/ c mice. ${ }^{55}$

Furthermore, a multi-antigenic nanovaccine against drug-resistant S.aureus was constructed using bacterial EVs. Skin infection experiments showed that the vaccine not only prevented superficial infection but also decreased bacterial invasiveness by promoting the maturation of dendritic cells (DC) and enhancing antigen presentation. ${ }^{56}$ Similarly, a DC-derived EV containing the Leishmania major antigen was investigated. The vesicle was proven to induce immunity against cutaneous leishmaniasis by promoting the proliferation of T-cells and secretion of IL-12, when used as a vaccine. ${ }^{57}$

Existing evidence therefore strongly supports the role of EVs in the pathological process of infectious diseases. Nevertheless, the feasibility of treatment and clinical application of EVs against inflammation need to be explored further.

\section{Inflammatory Skin Disorders}

Increasing research attention has been paid to the immunomodulatory role of EVs in inflammatory skin disorders, including psoriasis, atopic dermatitis, lichen planus, bullous pemphigoid, Systemic Lupus Erythematosus (SLE) and Systemic Sclerosis (SSc). ${ }^{5}$ A number of reviews have also highlighted that EVs secreted by immune or non-immune cells can affect both innate and adaptive immune responses. ${ }^{13,30,58-60}$ They can therefore be used as diagnostic and prognostic biomarkers or therapeutic agents in inflammatory skin disorders. ${ }^{6,55}$ More specifically, keratinocytes which are the main components of the epidermis, can also release EVs and regulate skin homeostasis, including immune responses and wound healing. ${ }^{11,62-64}$

Emerging evidence also suggests that miRNAs participate in the progression of immune diseases. ${ }^{59,65}$ Notably, EVs contain a large amount of miRNA cargo and were proven to be immunologically active and their levels were associated with disease activity in patients suffering from inflammatory skin diseases. ${ }^{6,60}$ Since EVs are present in body fluids mentioned previously, they can also be used to assess the progression of diseases and effect of treatment. A detailed account of the integral role of EVs in inflammatory skin diseases has been highlighted in previously published literature. ${ }^{59,61,66}$ Herein, focus was mainly directed to the role EVs in treating inflammatory skin diseases (See Table 1).

Importantly, EVs, as nano-vectors, offer a powerful delivery system for anti-inflammation therapy. ${ }^{59,61}$ For example, the nuclear factor $\kappa \mathrm{B}(\mathrm{NF}-\kappa \mathrm{B})$ transcription factors play a pivotal role in modulating the inflammatory cascades in various diseases, including sepsis and psoriasis. ${ }^{67}$ Therefore, an optogenetically engineered exosome system was implemented to load a large amount of the super-repressor inhibitor of NF-kB into EVs. These engineered EVs were able to reduce the mortality rate and systemic inflammation in septic mouse models, ${ }^{67}$ indicating the potent role of EVs in skin inflammation.

\section{Wound Healing and Scars}

The skin plays a crucial role in protecting the body against invasion by microorganisms and sensing environmental stimuli, including air pollutants. However, the skin is frequently damaged due to injury and may fail to heal in cases of diseases such as diabetes mellitus and usage of glucocorticoids or immunosuppressants. ${ }^{4}$ Although the last decades have witnessed tremendous progress in promoting wound healing, there are still challenges in the recovery of chronic wounds, since wound healing is a complex and dynamic physiological process that includes 
Table I The Role of EVs in Inflammatory Skin Diseases

\begin{tabular}{|c|c|c|c|c|}
\hline Disease & Source & Model & Effects & Reference \\
\hline SLE & $\begin{array}{l}\text { Mesenchymal } \\
\text { stem cell } \\
\text { (MSC) }\end{array}$ & $\begin{array}{l}\text { Fas-deficient-MRL } \\
\text { /lpr mice }\end{array}$ & $\begin{array}{l}\text { Transfered Fas to recipient MRL/lpr bone marrow MSCs (BMMSC) to reduce } \\
\text { levels of miR-29b, resulting in recovery of Dnmt I-mediated Notch I promoter } \\
\text { hypomethylation, thus improved MRL/ Ipr BMMSC function and ameliorated } \\
\text { osteopenia. }\end{array}$ & {$[5]$} \\
\hline \multirow[t]{4}{*}{$A D$} & \multirow[t]{2}{*}{ Adipose-MSC } & $A D$ mice & $\begin{array}{l}\text { Reduced pathological symptoms, the level of lgE and eosinophils in blood, and } \\
\text { the infiltration of mast cells, CD86+, and CD206+ cells in skin lesions. } \\
\text { Reduced inflammatory cytokines in skin lesions. }\end{array}$ & {$[143]$} \\
\hline & & $A D$ mice & $\begin{array}{l}\text { Reduced trans-epidermal water loss, enhanced stratum corneum hydration and } \\
\text { decreased the levels of inflammatory cytokines. } \\
\text { Induced the production of ceramides and dihydroceramides. }\end{array}$ & [144] \\
\hline & $\begin{array}{l}\text { Thymol- } \\
\text { treated } \\
\text { S. aureus }\end{array}$ & $\begin{array}{l}\text { Keratinocytes; AD } \\
\text { mice }\end{array}$ & $\begin{array}{l}\text { Alleviated AD-like skin lesion by decreasing epidermal/dermal thickness and } \\
\text { infiltration of eosinophils/mast cells, and inhibiting expression of pro- } \\
\text { inflammatory cytokine and chemokine genes. }\end{array}$ & [145] \\
\hline & $\begin{array}{l}\text { Lactobacillus } \\
\text { plantarum }\end{array}$ & $\begin{array}{l}\text { Keratinocytes; } A D \\
\text { mice }\end{array}$ & $\begin{array}{l}\text { Decreased IL- } 6 \text { and macrophage and restored cell viability in vitro; } \\
\text { Reduced epidermal thickening and the IL- } 4 \text { level. }\end{array}$ & [146] \\
\hline SSc & MSC & SSc mice & $\begin{array}{l}\text { Transfered miR-I5I-5p to the recipient BMMSCs to inhibit IL4R } \alpha \text { expression, } \\
\text { downregulated mTOR pathway to enhance osteogenic differentiation and } \\
\text { reduced adipogenic differentiation. } \\
\text { Rescued osteopenia, impaired BMMSCs, tight skin and immune disorders. }\end{array}$ & [66] \\
\hline
\end{tabular}

hemostasis, inflammation, angiogenesis, proliferation and remodeling. ${ }^{61,68}$ Since EVs have the potential to target specific recipient cells and a range of biomolecular cascades, they are believed to be promising therapeutic agents that may enhance wound healing. Recent reviews suggested that EVs cargo from multiple cell types, including MSC, human amniotic epithelial cells, endothelial progenitor cells, urine-derived stem cells, macrophages, keratinocytes and fibrocytes, have the capacity to specifically and potently modulate intracellular signaling pathways and inflammatory mediators that regulate cutaneous wound healing. ${ }^{64,65}$ In addition, exosomes in body fluids can also participate in skin wound healing. ${ }^{5}$

Previous research demonstrated that adipose mesenchymal stem cells (ASCs) -exosomes (Exos) can significantly accelerate wound healing and increase the production of collagen I and III in the early stages of wound healing. ${ }^{69}$ However, Exos can inhibit collagen expression to reduce scar formation in the late stages of wound healing, highlighting the complex function of EVs during the process. ${ }^{69}$ And Wang et al found that hypoxic ASCs exosomes could promote diabetic wounds healing and inhibit inflammation through PI3K/AKT signaling pathway. ${ }^{70} \mathrm{~A}$ recent study suggested that EVs derived from the same tissues in different species might be loaded with similar contents to accelerate tissue repair, regeneration and wound healing. ${ }^{71}$

With regard to re-engineering EVs to promote wound healing, Yang et al topically applied human umbilical cord-derived MSC (huMSC)-derived exosomes encapsulated in a thermosensitive Pluronic F-127 (PF-127) hydrogel to a cutaneous wound in a diabetic rat model. ${ }^{72}$ Compared to huMSC-exos, PF-127 only or control treatment, the combination treatment resulted in an accelerated rate of wound healing, enhanced regeneration of granulation tissue and upregulated expression of the vascular endothelial growth factor (VEGF) as well as the transforming growth factor (TGF) beta- $1 .{ }^{72}$ An addition study also developed an injectable, self-healing and antibacterial polypeptide-based FHE hydrogel (composed of Pluronic F127, oxidative hyaluronic acid and Poly- $\varepsilon$-L-lysine) with ASC-Exos. Notably, the FHE@exo hydrogel enhanced the healing of diabetic cutaneous wounds and reduced scar formation, in vivo. ${ }^{73} \mathrm{Wu}$ et al fabricated novel exosomes (mag-Bone Mesenchymal Stem Cells (BMSC) -Exos) from BMSCs, with the stimulation of Magnetic Nanoparticles (MNPs) and a Static Magnetic Field (SMF) to enhance wound healing. The mag-BMSC-Exos 
showed an enhanced potential of wound repair compared to BMSC-Exos, by improving angiogenesis and fibroblast function through the upregulation of miR-21-5p. ${ }^{74}$ Controlled-release exosomes derived from miR-126-3poverexpressing synovium MSCs combined with chitosan were tested and resulted in accelerated re-epithelialization, activated angiogenesis, and promotion of collagen maturity. ${ }^{75}$ Ao Shi et al developed platelets exosome product (PEP) enriched with TFG- $\beta$, which was incorporate with injectable surgical fibrin sealant. ${ }^{76}$ The PEP promoted chronic wound healing and complete skin regeneration in vivo and in vitro. Graphene-based nanomaterials (GBNs), as next-generation nanomaterials, have showed significant potential as the delivery system of MSCExos. ${ }^{77}$ A recent review summarized that GBNs have high surface area and loading rate to increase the effective dose and sustained release ability of MSC-Exos in wound healing. ${ }^{77}$ These studies therefore pave way for future research on the application of xenogeneic EVs and combination of other materials to achieve complete skin regeneration.

In addition to chronic wounds, an abnormal healing process can lead to hypertrophic scars and formation of keloids. ${ }^{78,79}$ Hypertrophic scars and keloids are cosmetic problems and may lead to functional challenges such as contractures, which significantly affect patients' quality of life. ${ }^{78}$ Conventional treatment of these diseases includes use of corticosteroids, scar revision, cryotherapy, radiotherapy, laser therapy and 5-fluorouracil. ${ }^{80}$ However, the treatment outcomes are still unsatisfactory. Previous studies showed that intravenous or local injection of ASC-Exos increased the ratio of collagen III: collagen I, TGF- $\beta 3$ : TGF- $\beta 1$ and MMP3: the Tissue inhibitor of Metalloproteinase (TIMP) 1, in mouse incisional wounds. The treatment also regulated the differentiation of fibroblasts, which reduced scar formation and remodeled the ECM. ${ }^{81}$ Further studies demonstrated that EVs promoted the proliferation and migration of fibroblasts and optimized collagen deposition through the PI3K/Akt signaling pathway. ${ }^{82}$ Additionally, EVs derived from human induced pluripotent stem cells-derived MSCs, menstrual blood-derived MSCs, hu-MSCs and human umbilical cord blood plasma, similarly reduced scar formation. ${ }^{83-87}$ Moreover, menstrual blood-MSC-Exos enhanced neoangiogenesis by increasing the levels of vascular endothelial growth factor A (VEGFA), accelerated reepithelialization by activating the NF- $\mathrm{kB}$ signaling pathway and reduced scar formation by decreasing the ratio of collagen I to collagen III. ${ }^{84}$ Furthermore, umbilical cord blood-
Exos containing miR-21-3p accelerated re-epithelialization, reduced the width of scars and enhanced angiogenesis by inhibiting phosphatase and tensin homolog (PTEN) and sprouty homolog 1 (SPRY1). ${ }^{85}$ The exosomal miRNAs of umbilical cord-MSCs (uMSCs) also reduced scar formation and suppressed the differentiation of myofibroblasts by inhibiting the TGF-ß2/SMAD2 pathway, in a mouse model of skin defect. ${ }^{86}$ A similar study showed that uMSCs-Exos suppressed the dermal fibroblastsmyofibroblast transition by inhibiting the TGF- $\beta 1 / \mathrm{Smad} 2 / 3$ signaling pathway. ${ }^{87}$

\section{Promoting Hair Growth}

Alopecia (one of the most common cases in dermatology) is a heterogeneous group of hair loss disorders including such conditions as androgenetic alopecia, alopecia areata and alopecia cicatrisata. ${ }^{88,89}$ Treatments of the disease mainly include use of minoxidil, finasteride, herbal extracts, intralesional injections of glucocorticoids, induction of contact allergy and hair transplantation, depending on the type of alopecia. ${ }^{88,90}$ Some new treatments have been developed, including use of platelet-rich plasma (PRP), adipose-derived stem cell therapy, keratinocyteconditioned media and low-level laser therapy (LLLT) ${ }^{88,90}$ However, none of these methods have been shown to give satisfactory results. Notably, hair growth and development of hair follicles (HF) involve interactions between epithelial and mesenchymal cells. Dermal Papilla Cells (DPCs) and Outer Root Sheath Cells (ORSCs) derived from the mesenchyme and epithelium, respectively, are key regulators of the development and growth of HF, with DPCs being more important. ${ }^{91}$ Recent research suggested that DPCs regulate the growth of HF mainly through a paracrine mechanism. Moreover, EVs derived from other cells were shown to also regulate hair growth (See Table 2). Therefore, EVs present a promising method of treating alopecia.

Cao et al injected NV extruded from ReNcell VM $(\mathrm{ReN})$ cells, a neural progenitor cell line, in a mouse model. ${ }^{92}$ The results showed that the NV promoted the proliferation of DPC and accelerated HF cycling transition by miR-100 to activate the $\mathrm{Wnt} / \beta$-catenin signaling pathway. ${ }^{92}$ This study therefore highlighted a possible method for the large-scale production of EVs in future.

\section{Pigmentation}

Vitiligo is an acquired chronic depigmenting disorder and is the most frequent cause of depigmentation worldwide, with 
Table 2 The Mechanisms of EVs in Promoting Hair Growth

\begin{tabular}{|c|c|c|c|c|c|}
\hline Source Cells & Disease & Modification & $\begin{array}{l}\text { Target } \\
\text { Cells }\end{array}$ & Effects & Reference \\
\hline MSC & Not specific & & DPC & $\begin{array}{l}\text { Increased DPC proliferation and migration, and elevated } \\
\text { the levels of Bcl-2, phosphorylated Akt and ERK. } \\
\text { In C57BL/ } 6 \text { mice, promoted the conversion from telogen } \\
\text { to anagen and increase expression of wnt } 3 \mathrm{a} \text {, wnt5a and } \\
\text { versican. }\end{array}$ & {$[147]$} \\
\hline $\begin{array}{l}\text { Human normal } \\
\text { fibroblast } \\
((\mathrm{hFB})\end{array}$ & Not specific & & $\begin{array}{l}\text { DPC and } \\
\text { ORSC }\end{array}$ & $\begin{array}{l}\text { Maintained the hair-generating activity of DPC through } \\
\text { Increasing wnt3a, -catenin, xin2 and LefI in DPC. } \\
\text { Promoted the migration, proliferation, and differentiation } \\
\text { of ORS cells and elongation of the hair shaft in human HFs. }\end{array}$ & {$[21]$} \\
\hline Macrophage & Not specific & & DPC & $\begin{array}{l}\text { Enhanced the hair follicle growth associated with Wnt3a, } \\
\text { Wnt7b, phosphorylated Akt and Bcl-2. } \\
\text { In Balb/c mice, promoted HF growth and increased hair } \\
\text { shaft size in a short period in human HFs. }\end{array}$ & {$[148]$} \\
\hline \multirow[t]{6}{*}{$\begin{array}{l}\text { Dermal papilla } \\
\text { cells }\end{array}$} & Not specific & & $\begin{array}{l}\text { DPC and } \\
\text { ORSC }\end{array}$ & $\begin{array}{l}\text { Induced anagen while delaying catagen, producing longer } \\
\text { hair shafts and larger bulges in mice. } \\
\text { Enhanced the proliferation and migration of ORSCs in vitro } \\
\text { mediated by } \beta \text {-catenin and Sonic hedgehog (Shh) signaling. }\end{array}$ & [149] \\
\hline & Not specific & & $\begin{array}{l}\text { Hair } \\
\text { follicle } \\
\text { stem cell } \\
\text { (HFSC) }\end{array}$ & $\begin{array}{l}\text { Regulated HFSCs proliferation and differentiation via genes } \\
\text { associated with cellular signal transduction, fatty acid } \\
\text { expression regulation, and cellular communication. } \\
\text { The miR-22-5p-LEFI axis may be a target. }\end{array}$ & [91] \\
\hline & Not specific & DP spheroids & & $\begin{array}{l}\text { Induced the progression of the hair follicle cycle from } \\
\text { telogen to anagen through upregulation of miR-2 I8-5p and } \\
\beta \text {-catenin in mice. }\end{array}$ & {$[150]$} \\
\hline & Not specific & DP spheroids & $\begin{array}{l}\text { DPC and } \\
\text { ORSC }\end{array}$ & $\begin{array}{l}\text { Promoted the proliferation of DPC and ORSC. } \\
\text { Increased hair shaft elongation in cultured human hair follicles. } \\
\text { Induced anagen from telogen and prolong anagen in mice. }\end{array}$ & [22] \\
\hline & Not specific & $\begin{array}{l}\text { Encapsulated in } \\
\text { oxidized sodium } \\
\text { alginate (OSA) } \\
\text { hydrogels }\end{array}$ & $\begin{array}{l}\text { Hair } \\
\text { matrix } \\
\text { cell }\end{array}$ & $\begin{array}{l}\text { Facilitated proliferation of hair matrix cells, prolonged anagen } \\
\text { phase and accelerated the regrowth of back hair. } \\
\text { May upregulate Wnt3a and } \beta \text {-catenin and downregulate BMP2. }\end{array}$ & {$[151]$} \\
\hline & Not specific & Low-passage DPC & $\begin{array}{l}\text { Hair } \\
\text { matrix } \\
\text { cells, and } \\
\text { ORSCs }\end{array}$ & $\begin{array}{l}\text { Accelerated HF elongation and cell proliferation activation } \\
\text { through miR-140-5p activating BMP/TGF- } \beta \text { signaling } \\
\text { pathways. }\end{array}$ & [152] \\
\hline $\begin{array}{l}\text { Dermal } \\
\text { Fibroblasts (DF) }\end{array}$ & Not specific & Stimulated $D F$ & DPC & $\begin{array}{l}\text { Enhanced HF growth ex vivo. } \\
\text { Norrin is secreted by EVs-stimulated DPCs activating in } \\
\text { a noncell autonomous manner } \beta \text {-catenin pathway in } \\
\text { follicular keratinocytes and hair growth ex vivo. }\end{array}$ & {$[153]$} \\
\hline $\begin{array}{l}\text { Myeloid- } \\
\text { derived } \\
\text { suppressor } \\
\text { cells (MDSC). }\end{array}$ & $\begin{array}{l}\text { Alopecia } \\
\text { areata }\end{array}$ & & & $\begin{array}{l}\text { In AA mice, targeted skin-draining lymph nodes and cells in } \\
\text { the vicinity of remnant hair follicles and accompanied by } \\
\text { a strong increase in Treg, a slight increase in lymphocyte } \\
\text { apoptosis, reduced T helper proliferation and mitigated } \\
\text { cytotoxic activity. }\end{array}$ & {$[154]$} \\
\hline
\end{tabular}


an estimated prevalence from $0.5 \%$ to $2 \% .{ }^{93,94}$ Previous studies showed that keratinocyte-derived exosomes modulated melanogenesis in melanocytes. ${ }^{15-17}$ In addition, EVs carrying selected miRNAs are targeted and modulated in melanocytes. ${ }^{95}$ For instance, miR-330-5p in exosomes derived from keratinocytes could inhibit melanogenesis by decreasing the expression of MITF in melanocytes. ${ }^{18,95}$ However, other studies revealed that miR-3196 and miR203 upregulated melanogenesis by increasing the expression of either MITF or TYR. ${ }^{16}$ Moreover, a previous study showed that exosomes secreted by keratinocytes in vitiligo, had a weaker capacity to promote melanogenesis in melanocytes. Furthermore, miR-200c, which enhanced the expression of melanogenesis-related genes by suppressing SOX1 to activate $\beta$-catenin, was reported to be downregulated in exosomes from keratinocytes in vitiligo lesions. ${ }^{96}$ In fact, the Heat shock $70 \mathrm{kDa}$ protein (HSP70) chaperone was proven to play a role in progressive depigmentation in a vitiligo mouse model. Carrasco et al also suggested that the release of HSP70-containing vesicles derived from melanocytes may contribute to the disease.

Furthermore, disorder of hyperpigmentation is arising from hyperfunctional melanocytes that deposit excessive amounts of melanin in the epidermis and dermis. Downregulation of the H19 non-coding RNA is believed to stimulate melanogenesis in melasma patients. ${ }^{18} \mathrm{Kim}$ et al also suggested that miR-675, derived from keratinocyte-Exos, could target MITF and was involved in H19stimulated melanogenesis. ${ }^{18}$ In addition, Bin et al demonstrated that EVs enriched in fibronectin were involved in the survival of melanocytes, following UVB radiation. The study also showed that the extracellular space around melanocytes contained more fibronectin compared to normal skin, in the hyperpigmented lesions of melasma patients, suggesting that fibronectin is involved in maintaining melanocytes in pathological conditions. ${ }^{97}$ More studies are therefore required to uncover how EVs affect pigmentation in hyper- or hypopigmentary diseases.

\section{Skin Rejuvenation}

Skin aging is caused by both intrinsic and extrinsic factors (especially UV radiation) which result in wrinkles, a rough texture, laxity, telangiectasia and pigmentation. More importantly, skin aging increases the risk of skin diseases. ${ }^{98}$ Several hallmarks have been recognized during aging, including cellular senescence. ${ }^{99,100}$ Cellular senescence includes permanent arrest of the cell cycle and contributes to decline in the regenerative potential of tissues. ${ }^{101}$ Additionally, senescent cells can secrete SASP (Senescence-associated Secretory Phenotype), including proinflammatory cytokines and chemokines or release EVs to maintain or destroy skin homeostasis. ${ }^{100}$ Previous studies showed that senescent human dermal fibroblasts (HDFs) produce more EVs than young HDFs by elevating the activity of neutral sphingomyelinase (nSMase) and altering lysosomal activity, with a concomitant $>80 \%$ increase in all the miRNAs for pro-apoptotic proteins. Moreover, EVs derived from senescent HDF were shown to be less effective at supporting keratinocyte differentiation and barrier function than those obtained from young HDF. ${ }^{102,103}$ In addition, EVs and miRNAs could be transferred from dermal fibroblasts to keratinocytes in a 2D cell culture and in a 3D skin model. ${ }^{19}$ Consequently, EVs have received tremendous attention in anti-aging skin rejuvenation (See Table 3).

A recent study also showed that Cell-Engineered Nanovesicles (CENVs) have several advantages over conventional EVs with regard to mass production. ${ }^{104}$ The study applied CENVs by serial extrusion of human iPSCs to senescent human HDFs. The results showed that CENVs not only stimulated the proliferation and migration of both young and senescent HDFs but also restored the senescence-related changes in gene expression. This involved reducing the activity of SA- $\beta-G a l$ in senescent HDFs and suppressing the expression of $\mathrm{p} 53$ and $\mathrm{p} 21$, which are key factors involved in cell cycle arrest, apoptosis and cellular senescence signaling pathways. ${ }^{105}$ Overall, these results suggested that iPSC-CENV may be a promising alternative to iPSC-exo for the treatment of skin aging.

\section{Skin Cancer}

Skin cancer is the most common type of malignancy in North America and is mainly divided into melanoma and nonmelanoma skin cancer. ${ }^{106}$ Nonmelanoma skin cancer includes Basal and Squamous Cell Carcinomas (BCC and SCC, respectively). ${ }^{107}$ Although melanoma accounts for only about $3 \%$ of all the skin cancers in the U.S, it is associated with approximately $75 \%$ of all skin cancerrelated deaths. ${ }^{108}$ And nonmelanoma skin cancers exert a huge physical and psychological burden to both patients and the society.

Particularly, carcinogenesis is a long-term process that includes initiation, promotion and progression of cancer. ${ }^{109}$ Therefore, specific markers of initiation and 
Table 3 The Mechanisms of EVs in Skin Rejuvenation

\begin{tabular}{|c|c|c|c|c|}
\hline Source Cells & Instructions & Models & Effects & Reference \\
\hline \multirow[t]{2}{*}{$\begin{array}{l}\text { Human induced } \\
\text { pluripotent stem } \\
\text { cells (iPSCs) }\end{array}$} & & $\begin{array}{l}\text { Human keratinocytes }(\mathrm{HaCaT}) \\
\text { HDF }\end{array}$ & $\begin{array}{l}\text { Increased } \mathrm{HaCaT} \text { proliferation and the viability and cell } \\
\text { cycle progression of } \mathrm{HaCaT} \text { and } \mathrm{HDFs} \text { by stimulating } \\
\text { phosphorylation of extracellular signal-regulated kinase } \\
\text { (ERK)-I/2. } \\
\text { enhanced the secretion of collagen in } \mathrm{HaCaT} \text { and HDFs. }\end{array}$ & {$[155]$} \\
\hline & & $\begin{array}{l}\text { Aged HDFs: irradiated by UVB } \\
(315 \mathrm{~nm}) \text { and subcultured for } \\
\text { over } 30 \text { passages }\end{array}$ & $\begin{array}{l}\text { Reduced the expression level of SA- } \beta-\text { Gal and MMP-I/3 and } \\
\text { restored the collagen type I expression in senescent HDFs. }\end{array}$ & {$[156]$} \\
\hline $\begin{array}{l}\text { Three- } \\
\text { dimensional } \\
\text { HDFs spheroids }\end{array}$ & $\begin{array}{l}\text { Needle-free } \\
\text { injector }\end{array}$ & $\begin{array}{l}\text { UVB-exposed HDFs; } \\
\text { Photoaging nude mice }\end{array}$ & $\begin{array}{l}\text { Expressed a higher level of TIMP-I and increased } \\
\text { procollagen type I expression and a significant decrease in } \\
\text { MMP-I expression by downregulating tumor necrosis } \\
\text { factor-alpha (TNF- } \alpha \text { ) and upregulating TGF- } \beta \text {, compared } \\
\text { with 2D HDF-Exos. }\end{array}$ & [157] \\
\hline $\begin{array}{l}\text { Human adipose- } \\
\text { derived stem cell }\end{array}$ & & Photo-damaged HDF & $\begin{array}{l}\text { Suppressed the overexpression of MMP-I, }-2,-3 \text { and-9 } \\
\text { induced by UVB irradiation and enhanced the expression of } \\
\text { collagen types I, II, III and V and elastin. } \\
\text { Upregulate TIMP-I and TGF- } \beta \text { I. }\end{array}$ & [158] \\
\hline $\begin{array}{l}\text { Embryonic stem } \\
\text { cells(ESC) }\end{array}$ & & Senescent HDFs & $\begin{array}{l}\text { Contained mmu-miR-29la-3p inhibited the HDFs } \\
\text { senescence through the TGF- } \beta \text { receptor } 2 \text { pathway. }\end{array}$ & [159] \\
\hline
\end{tabular}

progression are required to facilitate early detection of metastatic melanoma, in turn improving clinical intervention and patient survival. ${ }^{110}$ It is worth mentioning that liquid biopsy appears to be a new diagnostic method for cancer, which avoids painful tissue biopsies or harmful imaging method. ${ }^{111}$ The most common circulating markers are circulating tumour cells, circulating tumor specific nucleic acids, EVs and autoantibodies. ${ }^{111}$ Since EVs offer stable and abundant vehicles for testing and can be enriched or manipulated through diverse technologies, EVs have great potential as diagnostic and prognostic markers for cancer. ${ }^{111-114}$

Notably, the most widely studied pathological function of exosomes includes their modulatory roles in tumor biology. Exosomes shed by tumor cells are involved in the process of carcinogenesis, including tumor angiogenesis, Epithelial-to-mesenchymal Transition (EMT), tumor immunosuppression, formation of pre-metastatic niches and drug resistance. ${ }^{58,114-116}$ Raghavendra et al comprehensively reviewed the role of EVs in the metastasis and progression of melanoma. ${ }^{110}$ Briefly, cancer cells actively release EVs which convey bioinformation (such as miRNA and proteins) to neighboring cancer cells or benign cells, thus mediating protumor processes such as angiogenesis, immune regulation and modification of tissue microenvironments, contributing to the development and metastasis of cancer. ${ }^{11,58,110}$ Several studies have also shown that various miRNAs and proteins involved in cell growth, development, migration, metastasis and apoptosis are highly expressed in EVs released from melanoma cells. ${ }^{117-120}$

In addition to melanoma, Tumor-derived exosomes (TDEs) in Head and Neck Squamous Cell Carcinoma (HNSCC) are also involved in cancer initiation, invasion and progression, therapeutic application and resistance to treatment. ${ }^{121}$ Radiation is a common form of therapy in HNSCC. ${ }^{122}$ However, it was reported that radiation itself may increase the motility of cancer cells, thus increasing their invasion and migratory capacity. ${ }^{123}$ It was also reported that radiation can increase the release of exosomes in HNSCC cell lines and enhance the uptake of exosomes by recipient cells. Therefore, exosomes from HNSCC cells confer pro-survival effects on recipient cells by promoting proliferation and radioresistance. ${ }^{123}$ Moreover, Jelonek et al showed that exposure to ionizing radiation can change the exosomal cargo from HNSCC cells, which is involved in transcription, translation, protein turnover, cell division and cell signaling. ${ }^{124}$ Mutschelknaus et al further discovered radiation-induced changes in exosomal cargo. They reported that exosomes 
derived from irradiated HNSCC cells promoted AKTdependent migration in recipient cells. ${ }^{122}$ Although existing evidence suggests that exosomes may be involved in the pathogenesis of cancer, the exact role and mechanism of exosomes in SCC remains unclear.

Merkel Cell Carcinoma (MCC) is a rare and aggressive form of skin cancer that is associated with poor prognosis. $^{125}$ Therefore, biomarkers are urgently needed for early detection and effective treatment of MCC. Given that the Merkel Cell Polyomavirus (MCPyV) seems to be the major causal agent of MCC, the secretomes of two MCPyV-negative and two MCPyV-positive MCC cell lines were compared. ${ }^{126}$ The findings revealed 164 common proteins which were implicated in motility, metastasis and tumor progression. Such proteins included integrins, tetraspanins, intracellular signaling molecules, chaperones, proteasomal components and translation factors. ${ }^{126}$

These studies suggested that TDEs are present in all the body fluids in cancer patients and their levels change with disease progression or regression. They can therefore be used as diagnostic and therapeutic biomarkers. ${ }^{127,128}$

Moreover, the immunomodulatory efficacy of EVs can be enhanced by engineering advanced exosome-based vaccines. TDEs are characterized by tumor-homing properties and therefore hold great potential for use as drug carriers that not only target the primary tumor but also metastasis and the premetastatic niche. Morishita et al constructed an exosome-based tumor antigens-adjuvant co-delivery system using genetically engineered exosomes derived from murine melanoma B16-BL6 cells, containing endogenous tumor antigens and immunostimulatory $\mathrm{CpG}$ DNA. The CpG-SAV-exo-based (SAV: a fusion protein of streptavidin) vaccines were proven to possess stronger anti-tumor effects than simple co-administration of exosomes and CpG DNA. ${ }^{129}$

Besides the skin diseases mentioned above, StevensJohnson syndrome (SJS) and toxic epidermal necrolysis (TEN) are two severe drug-induced cutaneous reactions. A recent study demonstrate that exosomes isolated from the plasma of patients with SJS/TEN play a role in inducing keratinocyte apoptosis through miR-375-3p and may be new disease markers and therapeutics in SJS/TEN. ${ }^{130}$ Here, we summarized the contents of EVs and their roles in cutaneous lesions (Table 4).

\section{Clinical Trials}

There are currently 303 registered EVs-based or related clinical trials (11 July 2021), most of which have largely focused on the diagnostic, therapeutic or prognostic strategies in various cancers, cardiovascular diseases and neurodegenerative diseases. These clinical trials have so far demonstrated that autologous administration of EVs-based therapeutics and drug delivery platforms have no obvious toxicity and adverse side-effects, highlighting their safety and feasibility. ${ }^{115}$ Nonetheless, only a few clinical trials on cutaneous diseases, are currently underway. Notably, previous studies found that serum-derived exosomes accelerated cutaneous wound healing in BALB/c mice, thus a trial where plasma-derived autologous exosomes will be applied to the participants' ulcers daily, for 28 days, is currently underway. Cutaneous wound healing will then be evaluated based on the length, width and depth of the wound (ClinicalTrials.gov: NCT02565264). In another Phase 1/2A study, allogeneic EVs derived from normal donor MSCs, named AGLE-102, were administered to the wound surface of patients with Dystrophic Epidermolysis Bullosa (DEB). This trial aims to ascertain whether there is clinical benefit ( $>50 \%$ closure) in applying BM-MSC EVs to DEB wounds (ClinicalTrials. gov: NCT04173650). In addition, a pilot study will enroll 10 patients with bilateral venous ulcer refractory to conventional treatment. Subsequently, peri-wound injection of EVs derived from autologous serum will be performed to evaluate their efficacy. Specifically, peri-wound injection of the vesicles will be performed in a sterile environment and sterile gauze and an elastic-compression bandage will be applied. The contralateral ulcer will be treated with a standard dressing and an elastic compression bandage. The patients will be evaluated on an outpatient basis on day 3 and then weekly (ClinicalTrials.gov: NCT04652531). Moreover, an early feasibility Phase I clinical trial is currently investigating the efficacy of Hemopurifier in combination with pembrolizumab in clearing immunosuppressive exosomes in patients with advanced and/or metastatic HNSCC. The combination is aimed at reducing immune suppression and providing the combined benefit of immune restoration. Serial blood samples will be collected to evaluate the total exosome protein (TEP) levels, exosome profiles and the kinetics of exosome and TEP levels recovery. (ClinicalTrials.gov: NCT04453046). Furthermore, there are currently five registered clinical trials based on plant-EVs, including those derived from grapes, Citrus Limon, aloe and ginger (ClinicalTrials.gov: NCT01668849; NCT04698447; NCT03493984; NCT01294072; NCT04879810), focusing on oral mucositis associated with chemoradiation 
Table 4 The Contents of EVs and Their Roles in Cutaneous Lesions

\begin{tabular}{|c|c|c|c|}
\hline Diseases & Contents & Functions & Reference \\
\hline HSV-I & Viral RNA and STING & Enhanced its ability to spread between individuals & [46] \\
\hline S. aureus & Pore-forming $\alpha$-toxin & Induced $\mathrm{HaCaT}$ to form exosomes to infect other cells & {$[44,49]$} \\
\hline Leishmania & Leishmania major antigen & Induced immunity against cutaneous leishmaniasis & [57] \\
\hline M. sympodialis & Allergens from the fungus & Induced inflammatory cytokine responses in patients with atopic dermatitis & [5I] \\
\hline \multirow[t]{2}{*}{ SLE } & Fas & Improved MRL/ Ipr BMMSC function and ameliorated osteopenia & [6] \\
\hline & miR-I46a & Induced MSCs senescence & {$[160]$} \\
\hline \multirow[t]{2}{*}{ Psoriasis } & $\begin{array}{l}\text { let-7b-5p, miR-30e-5p, Inc- } \\
\text { RPII-70IH24.7, Inc-RNUI2 }\end{array}$ & May serve as biomarkers of PsA & {$[161,162]$} \\
\hline & PLA2 & Induced production of IL-22 and IL-I7A & [162] \\
\hline \multirow[t]{4}{*}{ SSc } & $\begin{array}{l}22 \text { dysregulated miRNAs and } \\
28 \text { I dysregulated IncRNAs }\end{array}$ & Provided novel clues for pathogenesis & [163] \\
\hline & Collagen-related microRNA & $\begin{array}{l}\text { Caused the delay of wound healing, resulting in higher susceptibility to pitting } \\
\text { scars and/or ulcers }\end{array}$ & {$[164]$} \\
\hline & SI00A8/ A9 & Suppressed the proliferation and migration of HDMEC & [165] \\
\hline & miR-I5I-5p & $\begin{array}{l}\text { Enhanced osteogenic differentiation and reduce adipogenic differentiation, } \\
\text { rescuing osteopenia, impaired BMSC, tight skin, and immune disorders }\end{array}$ & [166] \\
\hline $\begin{array}{l}\text { Wound } \\
\text { healing }\end{array}$ & $\mathrm{mi}-126-3 \mathrm{p}, \mathrm{miR}-205$ & Accelerated wound healing & {$[75,167]$} \\
\hline $\begin{array}{l}\text { Reducing scar } \\
\text { formation }\end{array}$ & $\begin{array}{l}\text { miR-2I, miR-23a, miR-I25b, } \\
\text { miR-2I-3p and miR-I45 }\end{array}$ & $\begin{array}{l}\text { Suppressed fibroblasts to myofibroblasts differentiation and prevented scar } \\
\text { formation }\end{array}$ & {$[85,86]$} \\
\hline \multirow[t]{2}{*}{ Hair growth } & miR-22-5p-LEFI & Regulated hair follicle stem cell proliferation & [9I] \\
\hline & Wnt3a, Wnt5a, Wntl I, Hh & Promoted telogen to anagen conversion; & \\
\hline Pigmentation & $\begin{array}{l}\mathrm{miR}-330-5 \mathrm{p}, \mathrm{miR}-3196, \mathrm{miR}- \\
203 \text { and } \mathrm{miR}-675\end{array}$ & Reduced melanin production and suppressed Tyrosinase activity & {$[16,18,95]$} \\
\hline Skin aging & miR-29la-3p & Inhibited human dermal fibroblasts senescence & [168] \\
\hline
\end{tabular}

treatment, cardiovascular risk factors, polycystic ovary syndrome, colon cancer and inflammatory bowel disease, respectively.

\section{Challenges and Perspectives}

So far, there is no approved treatment based on EVs and the results mentioned herein were mainly obtained from animal studies and in vitro assays. The major issue in the clinical application of EVs is the lack of robust and specific methods to isolate and analyze an enriched population of EVs among other nonspecific EVs due to several technological challenges. ${ }^{111,131}$ In addition, there are still several clinical challenges before using EVs in clinical practice.

\section{Technological Challenges}

There are several important issues that need to be considered including sample size determination, sample collection, storage and processing before analyzation. In this regard, the International Society for Extracellular Vesicles has provided recommendations for an evidencebased framework isolation and analysis of EVs. ${ }^{132}$ The isolation methods of EVs include ultra-speed centrifugation, ultrafiltration, immunoaffinity capture, charge neutralization-based polymer precipitation, size-exclusion chromatograph and microfluidic techniques. ${ }^{131,133,134}$ However, the existing methods of isolating EVs cannot meet the one-size-fits-all requirement. For example, ultracentrifugation remains the most commonly used isolation 
method. ${ }^{135}$ But it is time-consuming and requires precise equipment. In addition, during the course of high speed centrifugation, it may cause mechanical damage to EVs and protein aggregation. ${ }^{134}$ Since EVs include a wide variety of membrane vesicles partially overlapping in size, form and biogenesis, pure isolation of EVs remains cumbersome. $^{136}$ Therefore, coupling various isolation techniques needs to be considered for selective isolation and analyzation of a specific EV at high purity. ${ }^{134}$

During isolation of EVs, the contaminants may also be collected including lipoproteins, microbes, microsomes, DNA/chromatin and protein aggregates. ${ }^{132}$ Choosing a specific isolation method or combining these methods and DNase digestion may solve the above problems. ${ }^{132,134}$

Besides difficulties with isolation, precise measurement of EVs cargo is another challenge. ${ }^{112}$ EVs have abundant cargo, among them, miRNAs have gained significant attention in diagnosing diseases, therefore detecting miRNAs accurately seems to be important. However, some of the detection methods may not have enough accuracy and sensitivity due to the lower abundance of cargo. ${ }^{65}$

And the different methods of studies challenge the reproducibility of production of EVs. ${ }^{137}$ Therefore, there is an urgent need to improve standardization and reproducibility of the production of EVs. The International Society for Extracellular Vesicles (ISEV) proposed Minimal Information for Studies of Extracellular Vesicles ("MISEV") guidelines in 2018, which provided recommendations on experimental methods and minimal information on EVs research. ${ }^{138}$

\section{Clinical Challenges}

The condition of EVs may be affected by many genetic, physiological, and environmental factors, which may lead to EVs heterogeneity and change, thereby affecting analyzation and reproducibility. ${ }^{131,137,138}$ For instance, factors including age, gender, body mass index, medication use, physical activity and ethnicity will influence the level of EVs. ${ }^{112,132}$ Therefore, large well-characterized cohort studies are needed to assess the heterogenecity of EVs.

In addition, a few issues need to be addressed before using EVs in clinical practice. Such include latent toxicity, the dose-toxicity relationship, proper therapeutic approach, the treating dose and regimen. ${ }^{139}$ Future studies should therefore standardize these aspects in the preclinical stage, for a better understanding of EVs.

Another challenge is achieving scalable production of EVs for clinical application. Although there have been reports of rapid purification of exosomes on a largescale, ${ }^{140}$ this technique still requires expansion to different cell types and body fluids.

\section{Perspectives}

As mentioned above, EVs can be chemically or biologically modified to broaden, alter, or enhance their therapeutic capability. There are two main strategies that include manipulating the parent cells and directly functionalizing the EVs. ${ }^{3}$ The former strategy mainly entails genetic or metabolic engineering or introducing exogenous material that is subsequently incorporated into secreted EVs. On the other hand, the latter involves directly functionalizing EVs through such techniques as hydrophobic insertion, covalent surface chemistry and membrane permeabilization. Nonetheless, these techniques may affect the bioactivity and efficacy of engineered EVs.

Furthermore, novel EVs-like nanoparticles have been created to overcome the limitations of EVs. Such include bio-engineered EVs, EV-mimetic nanovesicles and EVbased semi-synthetic vesicles. ${ }^{141}$ Moreover, other nanoparticles have also shown great potential to treat diseases. For example, in order to improve the loading capacity and delivery efficiency of exosomes, hybrid exosome-like nanovesicles and membrane-camouflaged nanoparticles are designed. ${ }^{115}$ Notably, the loading efficiency of EVs is generally less than $30 \%$, which is much lower than that of synthetic nanoparticles (up to 94\%). ${ }^{15,142}$ In addition, Cheng et al developed an EV-like Metal-organic Framework (MOF) nanoparticle platform that showed high efficiency (up to 94\%) and high loading capacity (up to 50 times). Additionally, the EV-like nanoparticles can protect proteins against protease digestion and evade immune clearance. Furthermore, it was reported that the therapeutic protein, gelonin, within nanoparticles, significantly inhibited tumor growth and increased the therapeutic efficacy by 14 -fold. ${ }^{142}$

\section{Conclusion}

In conclusion, this article reviewed some basic characteristics of EVs and recent findings on the therapeutic role of EVs in skin conditions including infection, inflammatory skin disease, scar, alopecia, pigmentation, skin rejuvenation and skin cancer (Figure 2). Although the complex mechanisms driving the functions of EVs in these diseases remain elusive, there is evidence that EVs have the potential to diagnose and treat skin diseases. The data reviewed herein provide evidence that plant-derived EVs confer 
wound healing benefits, anti-senescence and antipigmentation of skin. Challenges such as low isolation and purification efficacy limit the preclinical and clinical application of EVs. Therefore, further investigations are needed to expand our understanding on the role of EVs as diagnostic markers and therapeutic agents for the management of skin diseases.

\section{Acknowledgments}

We would like to thank all the members of Li' Group who assisted in valuable suggestions on this manuscript.

\section{Author Contributions}

LL and LDX conceived the idea. YL drafted the manuscript. QX, LDX and JT carried out revisions of the manuscript. LL finalized the manuscript. All authors contributed to drafting or revising the article, have agreed on the journal to which the article will be submitted, gave final approval of the version to be published, and agreed to be accountable for all aspects of the work.

\section{Funding}

This work was supported by the 1.3 .5 project for disciplines of excellence, West China Hospital, Sichuan University (ZY2016106).

\section{Disclosure}

The authors report no conflicts of interest in this work.

\section{References}

1. Van Niel G, D'Angelo G, Raposo G. Shedding light on the cell biology of extracellular vesicles. Nat Rev Mol Cell Biol. 2018;19 (4):213-228. doi:10.1038/nrm.2017.125

2. van der Pol E, Böing AN, Harrison P, Sturk A, Nieuwland R. Classification, functions, and clinical relevance of extracellular vesicles. Pharmacol Rev. 2012;64(3):676-705. doi:10.1124/pr.112.005983

3. Armstrong JPK, Holme MN, Stevens MM. Re-engineering extracellular vesicles as smart nanoscale therapeutics. ACS Nano. 2017;11 (1):69-83. doi:10.1021/acsnano.6b07607

4. Proksch E, Brandner JM, Jensen JM. The skin: an indispensable barrier. Exp Dermatol. 2008;17(12):1063-1072. doi:10.1111/j.16000625.2008.00786.x

5. Xiong M, Zhang Q, Hu W, et al. The novel mechanisms and applications of exosomes in dermatology and cutaneous medical aesthetics. Pharmacol Res. 2021;166:105490. doi:10.1016/j.phrs.2021.105490

6. Chambers ES, Vukmanovic-Stejic M. Skin barrier immunity and ageing. Immunology. 2020;160(2):116-125. doi:10.1111/imm.13152

7. Damiani E, Ullrich SE. Progress in lipid research understanding the connection between platelet-activating factor, a UV-induced lipid mediator of in fl ammation, immune suppression and skin cancer. JPLR. 2016;63:14-27. doi:10.1016/j.plipres.2016.03.004

8. Pérez-Sánchez A, Barrajón-Catalán E, Herranz-López M, Micol V. Nutraceuticals for skin care: a comprehensive review of human clinical studies. Nutrients. 2018;10(4):1-22. doi:10.3390/nu10040403
9. Shin JW, Kwon SH, Choi JY, et al. Molecular mechanisms of dermal aging and antiaging approaches. Int J Mol Sci. 2019;20 (9):2126. doi:10.3390/ijms20092126

10. Rivera-Gonzalez G, Shook B, Horsley V. Adipocytes in skin health and disease. Cold Spring Harb Perspect Med. 2014;4(3): a015271-a015271. doi:10.1101/cshperspect.a015271

11. Khan AQ, Akhtar S, Prabhu KS, et al. Exosomes: emerging diagnostic and therapeutic targets in cutaneous diseases. Int J Mol Sci. 2020;21(23):1-27. doi:10.3390/ijms21239264

12. Than UTT, Leavesley DI, Parker TJ. Characteristics and roles of extracellular vesicles released by epidermal keratinocytes. $J$ Eur Acad Dermatol Venereol. 2019;33(12):2264-2272. doi:10.1111/ jdv. 15859

13. Nasiri G, Azarpira N, Alizadeh A, Goshtasbi S, Tayebi L. Shedding light on the role of keratinocyte-derived extracellular vesicles on skin-homing cells. Stem Cell Res Ther. 2020;11 (1):1-11. doi:10.1186/s13287-020-01929-8

14. Huang P, Bi J, Owen GR, et al. Keratinocyte microvesicles regulate the expression of multiple genes in dermal fibroblasts. J Invest Dermatol. 2015;135(12):3051-3059. doi:10.1038/jid.20 15.320

15. Clemmer DE, Ghatak S, Zhou X, et al. Exosome-mediated crosstalk between keratinocytes and macrophages in cutaneous wound healing. ACS Nano. 2020;14(10):12732-12748. doi:10.1021/ acsnano.0c03064

16. Cicero A, Delevoye C, Gilles-Marsens F, et al. Exosomes released by keratinocytes modulate melanocyte pigmentation. Nat Commun. 2015;6(May):1-8. doi:10.1038/ncomms8506

17. Takano K, Hachiya A, Murase D, et al. Quantitative changes in the secretion of exosomes from keratinocytes homeostatically regulate skin pigmentation in a paracrine manner. $J$ Dermatol. 2020;47(3):265-276. doi:10.1111/1346-8138.15202

18. Kim NH, Choi SH, Kim CH, Lee CH, Lee TR, Lee AY. Reduced MiR-675 in exosome in H19 RNA-related melanogenesis via MITF as a direct target. $J$ Invest Dermatol. 2014;134 (4):1075-1082. doi:10.1038/jid.2013.478

19. Terlecki-Zaniewicz L, Pils V, Bobbili MR, et al. Extracellular vesicles in human skin: cross-talk from senescent fibroblasts to keratinocytes by miRNAs. J Invest Dermatol. 2019;139 (12):2425-2436.e5. doi:10.1016/j.jid.2019.05.015

20. Wäster P, Eriksson I, Vainikka L, Rosdahl I, Öllinger K Extracellular vesicles are transferred from melanocytes to keratinocytes after UVA irradiation. Sci Rep. 2016;6(May):1-13. doi:10.1038/srep27890

21. Rajendran RL, Gangadaran P, Kwack MH, et al. Human fibroblast-derived extracellular vesicles promote hair growth in cultured human hair follicles. FEBS Lett. 2021:595(7):942-953. doi:10.1002/1873-3468.14050

22. Kwack MH, Seo CH, Gangadaran P, et al. Exosomes derived from human dermal papilla cells promote hair growth in cultured human hair follicles and augment the hair-inductive capacity of cultured dermal papilla spheres. Exp Dermatol. 2019;28 (7):854-857. doi:10.1111/exd.13927

23. Cong $\mathrm{M}$, Shen $\mathrm{M}, \mathrm{Wu} \mathrm{X}$, et al. Improvement of sensory neuron growth and survival via negatively regulating PTEN by miR-21$5 \mathrm{p}$-contained small extracellular vesicles from skin precursor-derived Schwann cells. Stem Cell Res Ther. 2021;12 (1):1-15. doi:10.1186/s13287-020-02125-4

24. Wu X, Wang L, Cong M, et al. Extracellular vesicles from skin precursor-derived Schwann cells promote axonal outgrowth and regeneration of motoneurons via $\mathrm{Akt} / \mathrm{mTOR} / \mathrm{p} 70 \mathrm{~S} 6 \mathrm{~K}$ pathway. Ann Transl Med. 2020;8(24):1640. doi:10.21037/atm-20-5965

25. Coumans FAW, Brisson AR, Buzas EI, et al. Methodological guidelines to study extracellular vesicles. Circ Res. 2017;120 (10):1632-1648. doi:10.1161/CIRCRESAHA.117.309417 
26. Galley JD, Besner GE. The therapeutic potential of breast milk-derived extracellular vesicles. Nutrients. 2020;12(3):745. doi:10.3390/nu12030745

27. da Silveira JC, Veeramachaneni DNR, Winger QA, Carnevale EM, Bouma GJ. Cell-secreted vesicles in equine ovarian follicular fluid contain mirnas and proteins: a possible new form of cell communication within the ovarian follicle. Biol Reprod. 2012;86(3):1-10. doi:10.1095/biolreprod.111.093252

28. Nair S, Tang KD, Kenny L, Punyadeera C. Salivary exosomes as potential biomarkers in cancer. Oral Oncol. 2018;84 (November2017):31-40. doi:10.1016/j.oraloncology.2018.07.001

29. Chen WW, Balaj L, Liau LM, et al. Beaming and droplet digital pcr analysis of mutant idh1 mrna in glioma patient serum and cerebrospinal fluid extracellular vesicles. Mol Ther Nucleic Acids. 2013;2(July):e109. doi:10.1038/mtna.2013.28

30. Schorey JS, Harding CV. Extracellular vesicles and infectious diseases: new complexity to an old story. J Clin Invest. 2016;126(4):1181-1189. doi:10.1172/JCI81132

31. Halperin W, Jensen WA. Ultrastructural changes during growth and embryogenesis in carrot cell cultures. J Ultrastruct Res. 1967;18(3-4):428-443. doi:10.1016/S0022-5320(67)80128-X

32. Cui Y, Gao J, He Y, Jiang L. Plant extracellular vesicles. Protoplasma. 2020;257(1):3-12. doi:10.1007/s00709-019-01435-6

33. Dad HA, Gu TW, Zhu AQ, Huang LQ, Peng LH. Plant exosome-like nanovesicles: emerging therapeutics and drug delivery nanoplatforms. Mol Ther. 2021;29(1):13-31. doi:10.1016/j. ymthe.2020.11.030

34. Herrmann IK, Wood MJA, Fuhrmann G. Extracellular vesicles as a next-generation drug delivery platform. Nat Nanotechnol. 2021;16(7):748-759. doi:10.1038/s41565-021-00931-2

35. Kim K, Yoo HJ, Jung JH, et al. Cytotoxic effects of plant sap-derived extracellular vesicles on various tumor cell types. J Funct Biomater. 2020;11(2):1-17. doi:10.3390/jfb11020022

36. Alfieri M, Leone A, Ambrosone A. Plant-derived nano and microvesicles for human health and therapeutic potential in nanomedicine. Pharmaceutics. 2021;13(4):498. doi:10.3390/ pharmaceutics 13040498

37. Teng Y, Ren Y, Sayed M, et al. Plant-derived exosomal micrornas shape the gut microbiota. Cell Host Microbe. 2018;24(5):637652.e8. doi:10.1016/j.chom.2018.10.001

38. You J, Jin S, Jong W. Bioactive materials isolation of cabbage exosome-like nanovesicles and investigation of their biological activities in human cells. Bioact Mater. 2021;6(12):4321-4332. doi:10.1016/j.bioactmat.2021.04.023

39. Yepes-Molina L, Martínez-Ballesta MC, Carvajal M. Plant plasma membrane vesicles interaction with keratinocytes reveals their potential as carriers. $J A d v$ Res. 2020;23:101-111. doi:10. 1016/j.jare.2020.02.004

40. Şahin F, Koçak P, Güneş MY, Özkan İ, Yıldırım E, Kala EY. In vitro wound healing activity of wheat-derived nanovesicles. Appl Biochem Biotechnol. 2019;188(2):381-394. doi:10.1007/s12010018-2913-1

41. Cho EG, Choi SY, Kim H, et al. Panax ginseng-derived extracellular vesicles facilitate anti-senescence effects in human skin cells: an eco-friendly and sustainable way to use ginseng substances. Cells. 2021;10(3):486. doi:10.3390/cells10030486

42. Lee R, Ko HJ, Kim K, et al. Anti-melanogenic effects of extracellular vesicles derived from plant leaves and stems in mouse melanoma cells and human healthy skin. J Extracell Vesicles. 2020;9(1):1703480. doi:10.1080/20013078.2019.1703480

43. Loureiro JA, Andrade S, Duarte A, et al. Resveratrol and grape extract-loaded solid lipid nanoparticles for the treatment of Alzheimer's disease. Molecules. 2017;22(2):1-16. doi:10.3390/ molecules 22020277
44. Wang J, Yao Y, Chen X, Wu J, Gu T, Tang X. Host derived exosomes-pathogens interactions: potential functions of exosomes in pathogen infection. Biomed Pharmacother. 2018;108 (September):1451-1459. doi:10.1016/j.biopha.2018.09.174

45. Dogrammatzis C, Deschamps T, Kalamvoki M. Biogenesis of extracellular vesicles during herpes simplex virus 1 infection: role of the CD63 tetraspanin. J Virol. 2018;93:2. doi:10.1128/ jvi.01850-18

46. Bello-Morales R, López-Guerrero JA. Extracellular vesicles in herpes viral spread and immune evasion. Front Microbiol. 2018;9(OCT):1-9. doi:10.3389/fmicb.2018.02572

47. Jun SH, Lee JH, Kim SI, et al. Staphylococcus aureus-derived membrane vesicles exacerbate skin inflammation in atopic dermatitis. Clin Exp Allergy. 2017;47(1):85-96. doi:10.1111/ cea. 12851

48. Hong SW, Kim MR, Lee EY, et al. Extracellular vesicles derived from Staphylococcus aureus induce atopic dermatitis-like skin inflammation. Allergy Eur J Allergy Clin Immunol. 2011;66 (3):351-359. doi:10.1111/j.1398-9995.2010.02483.x

49. Brown L, Wolf JM, Prados-Rosales R, Casadevall A. Through the wall: extracellular vesicles in gram-positive bacteria, mycobacteria and fungi. Nat Rev Microbiol. 2015;13(10):620-630. doi:10.1038/nrmicro3480

50. Choi EJ, Lee HG, Bae IH, et al. Propionibacterium acnes-derived extracellular vesicles promote acne-like phenotypes in human epidermis. J Invest Dermatol. 2018;138(6):1371-1379. doi:10.10 16/j.jid.2018.01.007

51. Vallhov H, Johansson C, Veerman RE, Scheynius A. Extracellular vesicles released from the skin commensal yeast malassezia sympodialis activate human primary keratinocytes. Front Cell Infect Microbiol. 2020;10. doi:10.3389/fcimb.2020.00006

52. Rodrigues ML, Nimrichter L, Oliveira DL, Nosanchuk JD, Casadevall A. Vesicular trans-cell wall transport in fungi: a mechanism for the delivery of virulence-associated macromolecules? Lipid Insights. 2008;21:27-40. doi:10.4137/ lpi.s 1000

53. Burza S, Croft SL, Boelaert M. Leishmaniasis. Lancet. 2018;392 (10151):951-970. doi:10.1016/S0140-6736(18)31204-2

54. Silverman JM, Reiner NE. Leishmania exosomes deliver preemptive strikes to create an environment permissive for early infection. Front Cell Infect Microbiol. 2011;1(January):26. doi:10.3389/fcimb.2011.00026

55. Olivier M, Zamboni DS. Leishmania Viannia guyanensis, LRV1 virus and extracellular vesicles: a dangerous trio influencing the faith of immune response during muco-cutaneous leishmaniasis. Curr Opin Immunol. 2020;66:108-113. doi:10.1016/j.coi.2020.08.004

56. Chen G, Bai Y, Li Z, Wang F, Fan X, Zhou X. Bacterial extracellular vesicle-coated multi-antigenic nanovaccines protect against drug-resistant Staphylococcus aureus infection by modulating antigen processing and presentation pathways. Theranostics. 2020;10(16):7131-7149. doi:10.7150/thno.44564

57. Schnitzer JK, Berzel S, Fajardo-Moser M, Remer KA, Moll H. Fragments of antigen-loaded dendritic cells (DC) and DC-derived exosomes induce protective immunity against Leishmania major. Vaccine. 2010;28(36):5785-5793. doi:10.1016/j.vaccine.2010.06.077

58. Robbins PD, Morelli AE. Regulation of immune responses by extracellular vesicles. Nat Rev Immunol. 2014;14(3):195-208. doi: $10.1038 /$ nri3622

59. Robbins PD, Dorronsoro A, Booker CN. Regulation of chronic inflammatory and immune processes by extracellular vesicles. $J$ Clin Invest. 2016;126(4):1173-1180. doi:10.1172/JCI81131

60. Kowal J, Tkach M. Dendritic Cell Extracellular Vesicles. Vol. 349. 1st ed. Elsevier Inc.; 2019 doi:10.1016/bs.ircmb.2019.08.005 
61. Shao S, Fang H, Li Q, Wang G. Extracellular vesicles in inflammatory skin disorders: from pathophysiology to treatment. Theranostics. 2020;10(22):9937-9955. doi:10.7150/thno.45488

62. Kilani RT, Chavez-mun C. Profile of exosomes related proteins released by differentiated and undifferentiated human keratinocytes. J Cell Physiol. 2009;221(1):221-231. doi:10.1002/jcp.21847

63. Piipponen M, Li D, Landén NX. The immune functions of keratinocytes in skin wound healing. Int J Mol Sci. 2020;21(22):1-26. doi:10.3390/ijms21228790

64. Ha DH, Kim HK, Lee J, et al. Mesenchymal stem/stromal cell-derived exosomes for immunomodulatory therapeutics and skin regeneration. Cells. 2020;9(5):4-6. doi:10.3390/cells9051 157

65. Mori MA, Ludwig RG, Garcia-Martin R, Brandão BB, Kahn CR Extracellular miRNAs: from biomarkers to mediators of physiology and disease. Cell Metab. 2019;30(4):656-673. doi:10.1016/j. cmet.2019.07.011

66. Wang WM, Wu C, Jin HZ. Exosomes in chronic inflammatory skin diseases and skin tumors. Exp Dermatol. 2019;28(3):2 13-218. doi:10.1111/exd.13857

67. Choi H, Kim Y, Mirzaaghasi A, et al. Exosome-based delivery of super-repressor $\mathrm{I} \kappa \mathrm{B} \alpha$ relieves sepsis-associated organ damage and mortality. Sci Adv. 2020;6(15):1-10. doi:10.1126/sciadv.aaz6980

68. Cabral J, Ryan AE, Griffin MD, Ritter T. Extracellular vesicles as modulators of wound healing. Adv Drug Deliv Rev. 2018;129:394-406. doi:10.1016/j.addr.2018.01.018

69. Hu L, Wang J, Zhou X, et al. Exosomes derived from human adipose mensenchymal stem cells accelerates cutaneous wound healing via optimizing the characteristics of fibroblasts. Sci Rep. 2016;6(August):1-11. doi:10.1038/srep32993

70. Wang J, Wu H, Peng Y, Zhao Y, Qin Y, Zhang Y. Hypoxia adipose stem cell-derived exosomes promote high-quality healing of diabetic wound involves activation of PI3K/Akt pathways. J Nanobiotechnology. 2021;19:1-13. doi:10.1186/s12951-02100942-0

71. Dong J, Wu Y, Zhang Y, Yu M, Tian W. Comparison of the therapeutic effect of allogeneic and xenogeneic small extracellular vesicles in soft tissue repair. Int $J$ Nanomedicine. 2020;15:6975-6991. doi:10.2147/IJN.S269069

72. Yang J, Chen Z, Pan D, Li H, Shen J. Umbilical cord-derived mesenchymal stem cell-derived exosomes combined pluronic F127 hydrogel promote chronic diabetic wound healing and complete skin regeneration. Int J Nanomedicine. 2020;15:5911-5926. doi:10.2147/IJN.S249129

73. Wang $\mathrm{C}$, Wang $\mathrm{M}, \mathrm{Xu} \mathrm{T}$, et al. Engineering bioactive self-healing antibacterial exosomes hydrogel for promoting chronic diabetic wound healing and complete skin regeneration. Theranostics. 2019;9(1):65-76. doi:10.7150/thno.29766

74. Wu D, Kang L, Tian J, et al. Exosomes derived from bone mesenchymal stem cells with the stimulation of $\mathrm{Fe} 3 \mathrm{O} 4$ nanoparticles and static magnetic field enhance wound healing through upregulated miR-21-5p. Int J Nanomedicine. 2020;15:7979-7993. doi:10.2147/IJN.S275650

75. Tao SC, Guo SC, Li M, Ke QF, Guo YP, Zhang CQ. Chitosan Wound Dressings Incorporating Exosomes Derived from MicroRNA-126-Overexpressing Synovium Mesenchymal Stem Cells Provide Sustained Release of Exosomes and Heal FullThickness Skin Defects in a Diabetic Rat Model. Stem Cells Transl Med. 2017;6(3):736-747. doi:10.5966/sctm.2016-0275.

76. Shi A, Li J, Qiu X, et al. TGF- $\beta$ loaded exosome enhances ischemic wound healing in vitro and in vivo. Theranostics. 2021;11(13):6616-6631. doi:10.7150/thno.57701

77. Wang Y. Advances on graphene-based nanomaterials and mesenchymal stem cell-derived exosomes applied in cutaneous wound healing. Int J Nanomedicine. 2021;16:2647-2665.
78. Lee HJ, Jang YJ. Recent understandings of biology, prophylaxis and treatment strategies for hypertrophic scars and keloids. Int J Mol Sci. 2018;19(3):711. doi:10.3390/ijms19030711

79. Zhang T, Wang XF, Wang ZC, et al. Current potential therapeutic strategies targeting the TGF- $\beta /$ Smad signaling pathway to attenuate keloid and hypertrophic scar formation. Biomed Pharmacother. 2020;129(3):110287. doi:10.1016/j.biopha.2020.110287

80. Lin S, Quan G, Hou A, et al. Strategy for hypertrophic scar therapy: improved delivery of triamcinolone acetonide using mechanically robust tip-concentrated dissolving microneedle array. J Control Release. 2019;306:69-82. doi:10.1016/j. jconrel.2019.05.038

81. Wang L, Hu L, Zhou X, et al. Exosomes secreted by human adipose mesenchymal stem cells promote scarless cutaneous repair by regulating extracellular matrix remodelling. Sci Rep. 2017;7(1):1-12. doi:10.1038/s41598-017-12919-x

82. Zhang W, Bai X, Zhao B, et al. Cell-free therapy based on adipose tissue stem cell-derived exosomes promotes wound healing via the PI3K/Akt signaling pathway. Exp Cell Res. 2018;370 (2):333-342. doi:10.1016/j.yexcr.2018.06.035

83. Zhang J, Guan J, Niu X, et al. Exosomes released from human induced pluripotent stem cells-derived MSCs facilitate cutaneous wound healing by promoting collagen synthesis and angiogenesis $J$ Transl Med. 2015;13(1):1-14. doi:10.1186/s12967-015-0417-0

84. Dalirfardouei R, Jamialahmadi K, Jafarian AH, Mahdipour E. Promising effects of exosomes isolated from menstrual blood-derived mesenchymal stem cell on wound-healing process in diabetic mouse model. J Tissue Eng Regen Med. 2019;13 (4):555-568. doi:10.1002/term.2799

85. $\mathrm{Hu}$ Y, Rao SS, Wang ZX, et al. Exosomes from human umbilical cord blood accelerate cutaneous wound healing through miR-21$3 \mathrm{p}$-mediated promotion of angiogenesis and fibroblast function. Theranostics. 2018;8(1):169-184. doi:10.7150/thno.21234

86. Fang $\mathrm{S}, \mathrm{Xu} \mathrm{C}$, Zhang $\mathrm{Y}$, et al. Umbilical Cord-Derived Mesenchymal Stem Cell-Derived Exosomal MicroRNAs Suppress Myofibroblast Differentiation by Inhibiting the Transforming Growth Factor- $\beta /$ SMAD2 Pathway During Wound Healing. Stem Cells Transl Med. 2016;5(10):1425-1439. doi:10.5966/sctm.2015-0367

87. Hu J, Chen Y, Huang Y, Su Y. Human umbilical cord mesenchymal stem cell-derived exosomes suppress dermal fibroblastsmyofibroblats transition via inhibiting the TGF- $\beta 1 / \mathrm{Smad} 2 / 3$ signaling pathway. Exp Mol Pathol. 2020;115:104468. doi:10.1016/j.yexmp.2020.104468

88. Adil A, Godwin M. The effectiveness of treatments for androgenetic alopecia: a systematic review and meta-analysis. $J \mathrm{Am}$ Acad Dermatol. 2017;77(1):136-141.e5. doi:10.1016/j.jaad.2017.02.054

89. Taghiabadi E, Nilforoushzadeh MA, Aghdami N. Maintaining hair inductivity in human dermal papilla cells: a review of effective methods. Skin Pharmacol Physiol. 2020;33(5):280-292. doi:10.1159/000510152

90. Progress M, Gilhar A, Etzioni A, Paus R. Alopecia areata. N Engl $J$ Med. 2012;366:1515-1525.

91. Yan H, Gao Y, Ding Q, et al. Exosomal micro RNAs derived from dermal papilla cells mediate hair follicle stem cell proliferation and differentiation. Int J Biol Sci. 2019;15(7):1368-1382. doi:10. 7150/ijbs.33233

92. Cao L, Tian T, Huang Y, et al. Neural progenitor cell-derived nanovesicles promote hair follicle growth via miR-100. JNanobiotechnology. 2021;19(1):1-13. doi:10.1186/s12951-020-00757-5

93. Rodrigues M, Ezzedine K, Hamzavi I, Pandya AG, Harris JE. New discoveries in the pathogenesis and classification of vitiligo. $\mathrm{J} \mathrm{Am}$ Acad Dermatol. 2017;77(1):1-13. doi:10.1016/j.jaad.2016.10.048

94. Ezzedine K, Eleftheriadou V, Whitton M, Van Geel N. Vitiligo. Lancet. 2015;386(9988):74-84. doi:10.1016/S0140-6736(14) 60763-7 
95. Liu Y, Xue L, Gao H, et al. Exosomal miRNA derived from keratinocytes regulates pigmentation in melanocytes. $J$ Dermatol Sci. 2019;93(3):159-167. doi:10.1016/j.jdermsci.2019.02.001

96. Zhao C, Wang D, Wang X, et al. Down-regulation of exosomal miR-200c derived from keratinocytes in vitiligo lesions suppresses melanogenesis. $J$ Cell Mol Med. 2020;24(20): 12164-12175. doi: $10.1111 /$ jcmm. 15864

97. Bin BH, Kim DK, Kim NH, et al. Fibronectin-containing extracellular vesicles protect melanocytes against ultraviolet radiation-induced cytotoxicity. J Invest Dermatol. 2016;136 (5):957-966. doi:10.1016/j.jid.2015.08.001

98. Gu Y, Han J, Jiang C, Zhang Y. Biomarkers, oxidative stress and autophagy in skin aging. Ageing Res Rev. 2020;59 (February):101036. doi:10.1016/j.arr.2020.101036

99. López-Otín C, Blasco MA, Partridge L, Serrano M, Kroemer G. The hallmarks of aging. Cell. 2013;153(6):1194. doi:10.1016/j. cell.2013.05.039

100. Toutfaire M, Bauwens E, Debacq-Chainiaux F. The impact of cellular senescence in skin ageing: a notion of mosaic and therapeutic strategies. Biochem Pharmacol. 2017;142:1-12. doi:10. 1016/j.bcp.2017.04.011

101. Hernandez-Segura A, Nehme J, Demaria M. Hallmarks of cellular senescence. Trends Cell Biol. 2018;28(6):436-453. doi:10.1016/j. tcb.2018.02.001

102. Choi EJ, Kil IS, Cho EG. Extracellular vesicles derived from senescent fibroblasts attenuate the dermal effect on keratinocyte differentiation. Int J Mol Sci. 2020;21(3):1022. doi:10.3390/ ijms21031022

103. Terlecki-Zaniewicz L, Lämmermann I, Latreille J, et al. Small extracellular vesicles and their miRNA cargo are anti-apoptotic members of the senescence-associated secretory phenotype. Aging (Albany NY). 2018;10(5):1103-1132. doi:10.18632/aging.101452

104. Cha H, Hong S, Park JH, Park HH. Stem cell-derived exosomes and nanovesicles: promotion of cell proliferation, migration, and anti-senescence for treatment of wound damage and skin ageing. Pharmaceutics. 2020;12(12):1-18. doi:10.3390/pharmaceutics 12121135

105. Lee H, Cha H, Park JH. Derivation of cell-engineered nanovesicles from human induced pluripotent stem cells and their protective effect on the senescence of dermal fibroblasts. Int J Mol Sci. 2020;21(1):343. doi:10.3390/ijms21010343

106. Gandhi SA, Kampp J. Skin cancer epidemiology, detection, and management. Med Clin North Am. 2015;99(6):1323-1335. doi:10.1016/j.mcna.2015.06.002

107. Chen AC, Martin AJ, Choy B, et al. A phase 3 randomized trial of nicotinamide for skin-cancer chemoprevention. $N$ Engl J Med. 2015;373(17):1618-1626. doi:10.1056/nejmoa1506197

108. Narayanan DL, Saladi RN, Fox JL. Ultraviolet radiation and skin cancer. Int J Dermatol. 2010;49(9):978-986. doi:10.1111/j.13654632.2010.04474.x

109. Singh M, Suman S, Shukla Y. New enlightenment of skin cancer chemoprevention through phytochemicals: in vitro and in vivo studies and the underlying mechanisms. Biomed Res Int. 2014;2014(iv):1-18. doi:10.1155/2014/243452

110. Raghavendra G, Robertson BM, Iyer S, Barry J, Dinavahi SS, Robertson GP. The role of exosomes in metastasis and progression of melanoma. Cancer Treat Rev. 2020;85:101975. doi:10. 1016/j.ctrv.2020.101975

111. Soda N, Rehm BHA, Sonar P, Nguyen NT, Shiddiky MJA. Advanced liquid biopsy technologies for circulating biomarker detection. J Mater Chem B. 2019;7(43):6670-6704. doi:10.1039/ c9tb01490j

112. Mathew M, Zade M, Mezghani N, Patel R, Wang Y, MomenHeravi F. Extracellular vesicles as biomarkers in cancer immunotherapy. Cancers (Basel). 2020;12(10):1-21. doi:10.33 90/cancers 12102825
113. Wang Z, Chen JQ, Liu J, Tian L. Exosomes in tumor microenvironment: novel transporters and biomarkers. J Transl Med. 2016;14(1):1-9. doi:10.1186/s12967-016-1056-9

114. Wu M, Wang G, Hu W, Yao Y, Yu XF. Emerging roles and therapeutic value of exosomes in cancer metastasis. Mol Cancer. 2019;18(1):1-11. doi:10.1186/s12943-019-0964-8

115. Lu M, Huang Y. Bioinspired exosome-like therapeutics and delivery nanoplatforms. Biomaterials. 2020;242(November2019):119925. doi:10.1016/j.biomaterials.2020.119925

116. Namee NM, O'Driscoll L. Extracellular vesicles and anti-cancer drug resistance. Biochim Biophys Acta Rev Cancer. 2018;1870 (2):123-136. doi:10.1016/j.bbcan.2018.07.003

117. Pfeffer S, Grossmann K, Cassidy P, et al. Detection of exosomal miRNAs in the plasma of melanoma patients. $J$ Clin Med. 2015;4 (12):2012-2027. doi: $10.3390 / \mathrm{jcm} 4121957$

118. Tengda L, Shuping L, Mingli G, et al. Serum exosomal microRNAs as potent circulating biomarkers for melanoma. Melanoma Res. 2018;28(4):295-303. doi:10.1097/CMR.00000 00000000450

119. Xiao D, Ohlendorf $\mathrm{J}$, Chen $\mathrm{Y}$, et al. Identifying mRNA, MicroRNA and protein profiles of melanoma exosomes. PLoS One. 2012;7(10):e46874. doi:10.1371/journal.pone.0046874

120. Lazar I, Clement E, Ducoux-Petit M, et al. Proteome characterization of melanoma exosomes reveals a specific signature for metastatic cell lines. Pigment Cell Melanoma Res. 2015;28 (4):464-475. doi:10.1111/pcmr.12380

121. Xiao C, Song F, Zheng YL, Lv J, Wang QF, Xu N. Exosomes in head and neck squamous cell carcinoma. Front Oncol. 2019;9 (September):1-13. doi:10.3389/fonc.2019.00894

122. Mutschelknaus L, Azimzadeh O, Heider T, et al. Radiation alters the cargo of exosomes released from squamous head and neck cancer cells to promote migration of recipient cells. Sci Rep. 2017;7(1):1-13. doi:10.1038/s41598-017-12403-6

123. Mutschelknaus L, Peters C, Winkler K, et al. Exosomes derived from squamous head and neck cancer promote cell survival after ionizing radiation. PLoS One. 2016;11(3):1-16. doi:10.1371/journal.pone. 0152213

124. Jelonek K, Wojakowska A, Marczak L, et al. Ionizing radiation affects protein composition of exosomes secreted in vitro from head and neck squamous cell carcinoma. Acta Biochim Pol. 2015;62(2):265-272. doi:10.18388/abp.2015_970

125. Konstatinell A, Coucheron DH, Sveinbjørnsson B, Moens U. MicroRNAs as potential biomarkers in merkel cell carcinoma. Int J Mol Sci. 2018;19(7):1873. doi:10.3390/ijms19071873

126. Konstantinell A, Bruun JA, Olsen R, et al. Secretomic analysis of extracellular vesicles originating from polyomavirus-negative and polyomavirus-positive Merkel cell carcinoma cell lines. Proteomics. 2016;16(19):2587-2591. doi:10.1002/pmic.201600 223

127. Czystowska-Kuzmicz M, Whiteside TL. The potential role of tumor-derived exosomes in diagnosis, prognosis, and response to therapy in cancer. Expert Opin Biol Ther. 2021;21 (2):241-258. doi:10.1080/14712598.2020.1813276

128. Ebnoether E, Muller L. Diagnostic and therapeutic applications of exosomes in cancer with a special focus on head and neck squamous cell carcinoma (HNSCC). Int $J$ Mol Sci. 2020;21 (12):1-18. doi:10.3390/ijms21124344

129. Morishita M, Takahashi Y, Matsumoto A, Nishikawa M, Takakura Y. Exosome-based tumor antigens-adjuvant codelivery utilizing genetically engineered tumor cell-derived exosomes with immunostimulatory $\mathrm{CpG}$ DNA. Biomaterials. 2016;111:55-65. doi:10.1016/j.biomaterials.2016.09.031

130. Zhang C, Zhu ZL, Gao JX, et al. Plasma exosomal miR-375-3p regulates mitochondria-dependent keratinocyte apoptosis by targeting XIAP in severe drug-induced skin reactions. Sci Transl Med. 2020;12(574):1-14. doi:10.1126/scitranslmed.aaw6142 
131. Boriachek K, Islam MN, Möller A, et al. Biological functions and current advances in isolation and detection strategies for exosome nanovesicles. Small. 2018;14(6):1-21. doi:10.1002/smll.201702 153

132. Witwer KW, Buzás EI, Bemis LT, et al. Standardization of sample collection, isolation and analysis methods in extracellular vesicle research. J Extracell Vesicles. 2013;2(1):20360. doi:10.3402/jev. v2i0.20360

133. Li P, Kaslan M, Lee SH, Yao J, Gao Z. Progress in exosome isolation techniques. Theranostics. 2017;7(3):789-804. doi:10. 7150/thno.18133

134. Yang D, Zhang W, Zhang H, et al. Progress, opportunity, and perspective on exosome isolation - Efforts for efficient exosome-based theranostics. Theranostics. 2020;10(8):36 84-3707. doi:10.7150/thno.41580

135. Gardiner C, Vizio D, Sahoo S, et al. Techniques used for the isolation and characterization of extracellular vesicles: results of a worldwide survey. $J$ Extracell Vesicles. 2016;5(1):32945. doi:10.3402/jev.v5.32945

136. Shah R, Patel T, Freedman JE. Circulating extracellular vesicles in human disease. $N$ Engl J Med. 2018;379(10):958-966. doi:10. 1056/nejmra1704286

137. Clayton A, Boilard E, Buzas EI, et al. Considerations towards a roadmap for collection, handling and storage of blood extracellular vesicles. $J$ Extracell Vesicles. 2019;8(1):1647027. doi:10.1080/20013078.2019.1647027

138. Théry C, Witwer KW, Aikawa E, et al. Minimal information for studies of extracellular vesicles 2018 (MISEV2018): a position statement of the international society for extracellular vesicles and update of the MISEV2014 guidelines. J Extracell Vesicles. 2018;7 (1):1535750. doi:10.1080/20013078.2018.1535750

139. Colao IL, Corteling R, Bracewell D, Wall I. Manufacturing exosomes: a promising therapeutic platform. Trends Mol Med. 2018;24(3):242-256. doi:10.1016/j.molmed.2018.01.006

140. Liu C, Su C. Design strategies and application progress of therapeutic exosomes. Theranostics. 2019;9(4):1015-1028. doi:10.71 50/thno. 30853

141. Tsiapalis D, O’Driscoll L. Mesenchymal stem cell derived extracellular vesicles for tissue engineering and regenerative medicine applications. Cells. 2020;9(4):991. doi:10.3390/cells9040991

142. Cheng G, Li W, Ha L, et al. Self-assembly of extracellular vesicle-like metal-organic framework nanoparticles for protection and intracellular delivery of biofunctional proteins. $J \mathrm{Am} \mathrm{Chem}$ Soc. 2018;140(23):7282-7291. doi:10.1021/jacs.8b03584

143. Cho BS, Kim JO, Ha DH, Yi YW. Exosomes derived from human adipose tissue-derived mesenchymal stem cells alleviate atopic dermatitis. Stem Cell Res Ther. 2018;9(1):1-5. doi:10.1186/ s13287-018-0939-5

144. Shin K-O, Ha DH, Kim JO, et al. Exosomes from human adipose tissue-derived mesenchymal stem cells promote epidermal barrier repair by inducing de novo synthesis of ceramides in atopic dermatitis. Cells. 2020;9(3):680. doi:10.3390/cells9030680

145. Kwon H Il, Jeong NH, Jun SH, et al. Thymol attenuates the worsening of atopic dermatitis induced by Staphylococcus aureus membrane vesicles. Int Immunopharmacol. 2018;59(April): 301-309. doi:10.1016/j.intimp.2018.04.027

146. Kim MH, Choi SJ, Choi H Il, et al. Lactobacillus plantarum-derived extracellular vesicles protect atopic dermatitis induced by Staphylococcus aureus-derived extracellular vesicles. Allergy Asthma Immunol Res. 2018;10(5):516-532. doi:10.4168/ aair.2018.10.5.516

147. Rajendran RL, Gangadaran P, Bak SS, et al. Extracellular vesicles derived from MSCs activates dermal papilla cell in vitro and promotes hair follicle conversion from telogen to anagen in mice. Sci Rep. 2017;7(1):1-12. doi:10.1038/s41598017-15505-3
148. Rajendran RL, Gangadaran P, Seo CH, et al. Macrophage-derived extracellular vesicle promotes hair growth. Cells. 2020;9(4):856. doi:10.3390/cells9040856

149. Zhou L, Wang H, Jing J, Yu L, Wu X, Lu Z. Regulation of hair follicle development by exosomes derived from dermal papilla cells. Biochem Biophys Res Commun. 2018;500(2):325-332. doi:10.1016/j.bbrc.2018.04.067

150. Hu S, Li Z, Lutz H, et al. Dermal exosomes containing miR-218$5 \mathrm{p}$ promote hair regeneration by regulating $\beta$-catenin signaling. Sci Adv. 2020;6(30):eaba1685. doi:10.1126/sciadv.aba1685

151. Chen Y, Huang J, Chen R, et al. Sustained release of dermal papilla-derived extracellular vesicles from injectable microgel promotes hair growth. Theranostics. 2020;10(3):1454-1478. doi:10.7150/thno.39566

152. Chen Y, Huang J, Liu Z, et al. miR-140-5p in small extracellular vesicles from human papilla cells stimulates hair growth by promoting proliferation of outer root sheath and hair matrix cells. Front Cell Dev Biol. 2020;8(December):1-20. doi:10.3389/fcell.2020.593638

153. le Riche A, Aberdam E, Marchand L, et al. Extracellular vesicles from activated dermal fibroblasts stimulate hair follicle growth through dermal papilla-secreted norrin. Stem Cells. 2019;37 (9):1166-1175. doi:10.1002/stem.3043

154. Zöller M, Zhao K, Kutlu N, et al. Immunoregulatory effects of myeloid-derived suppressor cell exosomes in mouse model of autoimmune alopecia areata. Front Immunol. 2018;9(6):1279. doi:10.3389/fimmu.2018.01279

155. Kim S, Lee SK, Kim H, Kim TM. Exosomes secreted from induced pluripotent stem cell-derived mesenchymal stem cells accelerate skin cell proliferation. Int J Mol Sci. 2018;19 (10):3119. doi:10.3390/ijms19103119

156. Oh M, Lee J, Kim YJ, Rhee WJ, Park JH. Exosomes derived from human induced pluripotent stem cells ameliorate the aging of skin fibroblasts. Int J Mol Sci. 2018;19(6):1-18. doi:10.3390/ijms 19061715

157. Hu S, Li Z, Cores J, et al. Needle-free injection of exosomes derived from human dermal fibroblast spheroids ameliorates skin photoaging. ACS Nano. 2019;13(10):11273-11282. doi:10.1021/ acsnano.9b04384

158. Choi JS, Cho WL, Choi YJ, et al. Functional recovery in photo-damaged human dermal fibroblasts by human adipose-derived stem cell extracellular vesicles. $J$ Extracell Vesicles. 2019;8(1):1565885. doi:10.1080/20013078.2019.1565885

159. Xiong $\mathrm{M}$, Zhang Q, $\mathrm{Hu} \mathrm{W}$, et al. Exosomes from adipose-derived stem cells: the emerging roles and applications in tissue regeneration of plastic and cosmetic surgery. Front Cell Dev Biol. 2020;8 (September):1-17. doi:10.3389/fcell.2020.574223

160. Dong C, Zhou Q, Fu T, et al. Circulating exosomes derived-miR146a from systemic lupus erythematosus patients regulates senescence of mesenchymal stem cells. Biomed Res Int. 2019;2019:1-10. doi:10.1155/2019/6071308

161. Pasquali L, Svedbom A, Srivastava A, et al. Circulating microRNAs in extracellular vesicles as potential biomarkers for psoriatic arthritis in patients with psoriasis. J Eur Acad Dermatol Venereol. 2020;34(6):1248-1256. doi:10.1111/jdv.16203

162. Cheung KL, Jarrett R, Subramaniam S, et al. Psoriatic T cells recognize neolipid antigens generated by mast cell phospholipase delivered by exosomes and presented by CD1a. J Exp Med. 2016;213(11):2399-2412. doi:10.1084/JEM.20160258

163. Li L, Zuo X, Liu D, Luo H, Zhu H. The profiles of miRNAs and lncRNAs in peripheral blood neutrophils exosomes of diffuse cutaneous systemic sclerosis. J Dermatol Sci. 2020;98(2):88-97. doi:10.1016/j.jdermsci.2020.02.009

164. Nakamura K, Jinnin M, Harada M, et al. Altered expression of CD63 and exosomes in scleroderma dermal fibroblasts. J Dermatol Sci. 2016;84(1):30-39. doi:10.1016/j.jdermsci.2016. 06.013 
165. Li L, Zuo X, Xiao Y, Liu D, Luo H, Zhu H. Neutrophilderived exosome from systemic sclerosis inhibits the proliferation and migration of endothelial cells. Biochem Biophys Res Commun. 2020;526(2):334-340. doi:10.1186/s12943-0190964-8

166. Chen C, Wang D, Moshaverinia A, et al. Mesenchymal stem cell transplantation in tight-skin mice identifies miR-151-5p as a therapeutic target for systemic sclerosis. Cell Res. 2017;27(4):559-577. doi:10.1038/cr.20 17.11
167. Da Fonseca Ferreira A, Da Silva Cunha P, Carregal VM, et al. Extracellular vesicles from adipose-derived mesenchymal stem/stromal cells accelerate migration and activate AKT pathway in human keratinocytes and fibroblasts independently of mir-205 activity. Stem Cells Int. 2017;2017:9841035. doi:10.1155/2017/9841035

168. Bae YU, Son Y, Kim CH, et al. Embryonic stem cell-derived mmu-mir-291a-3p inhibits cellular senescence in human dermal fibroblasts through the TGF-B receptor 2 pathway. $J$ Gerontol. 2019;74(9):1359-67. doi:10.1093/gerona/gly208

\section{Publish your work in this journal}

The International Journal of Nanomedicine is an international, peerreviewed journal focusing on the application of nanotechnology in diagnostics, therapeutics, and drug delivery systems throughout the biomedical field. This journal is indexed on PubMed Central, MedLine, CAS, SciSearch ${ }^{\mathbb{R}}$, Current Contents ${ }^{\mathbb{R}} /$ Clinical Medicine, $^{2}$
Journal Citation Reports/Science Edition, EMBase, Scopus and the Elsevier Bibliographic databases. The manuscript management system is completely online and includes a very quick and fair peer-review system, which is all easy to use. Visit http://www.dovepress.com/ testimonials.php to read real quotes from published authors. 